\title{
México: las reformas del mercado desde una perspectiva histórica
}

\author{
Juan Carlos Moreno-Brid y Jaime Ros
}

Juan Carlos Moreno-Brid

Asesor regional,

Subsede de la CEPAL en México

• jcmoreno@un.org.mx

Jaime Ros

Profesor de Economía,

Universidad de Notre Dame,

Indiana

$\multimap$ ros.1@nd.edu

$\mathrm{E}$

ste trabajo pasa revista a las principales políticas de desarrollo aplicadas por México en los dos últimos siglos y a los problemas económicos enfrentados. Centrándose en cambios radicales de estrategia respecto al papel de los mercados y el Estado, sostiene que a menudo no se han reconocido los verdaderos obstáculos con que ha tropezado el desarrollo del país y que algo similar podría estar ocurriendo hoy. Para demostrarlo, examina las causas del estancamiento económico de México en gran parte del siglo XIX. Asimismo, analiza el período de expansión económica entre 1940 y 1981, que terminó tras un breve auge del petróleo. Examina en forma crítica el cambio profundo introducido en la estrategia de desarrollo a mediados del decenio de 1980 para enfrentar la crisis de la deuda externa asociada al aparente agotamiento de la sustitución de importaciones y de la industrialización impulsada por el Estado. Finalmente, ofrece algunas reflexiones sobre los desafíos que confronta actualmente la economía mexicana que, tras 15 años o más de reformas macroeconómicas, parece encontrarse entrampada en un escenario de bajo crecimiento. 


\section{Introducción}

Este artículo, que aborda desde una perspectiva histórica las políticas aplicadas en México y los problemas de ese país para alcanzar el desarrollo, reseña la evolución a largo plazo de la economía mexicana, destacando en especial algunas modificaciones radicales a la estrategia de desarrollo y el papel que desempeñaron el mercado y el Estado, particularmente en los últimos 20 años. Una de las tesis principales es que en el pasado a menudo no se supo reconocer los verdaderos obstáculos al desarrollo económico y que actualmente podría estar ocurriendo algo similar. El trabajo está estructurado de la siguiente manera. Tras esta breve introducción, en la sección II se considera el debate en torno a las causas del prolongado período de estancamiento económico vivido por México durante gran parte del siglo XIX. En la sección III se examina el largo período de expansión de la economía mexicana, que se inició a fines del siglo XIX con el porfiriato ${ }^{1}$ y terminó en 1981, tras el derrumbe de una breve bonanza petrolera. La sección IV analiza el desempeño de la economía mexicana a partir del cambio radical de la estrategia de desarrollo introducido a mediados del decenio de 1980. Finalmente, se ofrecen algunas reflexiones acerca de los retos que confronta la economía mexicana hoy en día, cuando tras casi más de dos décadas de haberse iniciado el proceso de reformas profundas, no logra insertarse en una senda de crecimiento elevado y sostenido. Más grave aún, en el trienio más reciente (2001-2003), el PIB real per cápita registró una caída en términos reales en tres años consecutivos, por primera vez en la historia moderna del país.

\section{II}

\section{Las reformas del mercado en el siglo XIX}

A mediados del siglo XVIII, México era quizá una de las regiones más prósperas del mundo y, sin duda, una de las colonias españolas más ricas de América; además, la productividad de su economía posiblemente superaba aquélla de la propia España. En el año 1800, el PIB per cápita mexicano era más o menos la mitad del de los Estados Unidos, la economía mexicana no tenía un carácter marcadamente agrario y el país contaba con una industria minera avanzada y un importante

$\square$ El presente trabajo es una versión ampliada y corregida de un ensayo publicado por los autores hace casi 10 años, cuando entró en vigor el Tratado de Libre Comercio (TLC) de América del Norte (véase Moreno-Brid y Ros, 1994). Fue presentado en la reunión de la Asociación de Economía de América Latina (ADEALC) realizada en Cholula, México, el 10 de octubre de 2003. Los autores agradecen la valiosa asistencia de Rubén Guerrero en el trabajo de investigación, así como los comentarios a la versión preliminar formulados por Ted Beatty, Rolando Cordera, Amitava Dutt, Julie Lennox, Ajit Singh, Carlos Tello, Samuel Valenzuela y Jeff Williamson. Las opiniones vertidas en el artículo no representan necesariamente las de las Naciones Unidas. sector manufacturero. El valor de las exportaciones se asemejaba al de su vecino del norte, por mucho que el PIB total equivalía más o menos a la mitad (Coatsworth, 1978). En el país se daban varias de las condiciones para un desarrollo capitalista acelerado. Aunque distara mucho de haberse completado la creación de una fuerza de trabajo industrial - ese proceso tan difícil y prolongado mediante el cual se rompen los lazos de la población con la tierra (Gerschenkron, 1952) - el proceso se encontraba en una etapa más avanzada que en muchos países europeos (especialmente de Europa central y oriental). En 1800, la participación relativamente importante de la industria manufacturera en el producto total, de $22,3 \%$ (cuadro 1 ), ${ }^{2}$ revela que en el país existía una masa crítica de empresarios industriales (cuadro 1).

\footnotetext{
${ }^{1}$ Los historiadores mexicanos han llamado "porfiriato" a los 33 años de dictadura de Porfirio Díaz (1877 a 1910).

${ }^{2}$ Según inEGi (1985), en 1790 la participación de la industria manufacturera en el empleo era del $10 \%$.
} 


\begin{tabular}{|c|c|c|c|c|c|c|}
\hline & 1800 & 1845 & 1860 & 1877 & 1895 & 1910 \\
\hline $\begin{array}{l}\text { PIB per cápita a precios consta } \\
\text { de } 1900 \text { (índice } 1800=100 \text { ) }\end{array}$ & 100,0 & 78,4 & 70,9 & 85,0 & 128,8 & 190,2 \\
\hline \multicolumn{7}{|l|}{$\%$ del PIB } \\
\hline Agricultura $^{\mathrm{a}}$ & 44,4 & 48,1 & 42,1 & 42,2 & 3,2 & 33,7 \\
\hline Minería & 8,2 & 6,2 & 9,7 & 1,4 & 6,3 & 8,4 \\
\hline Manufactura & 22,3 & 18,3 & 21,6 & 16,2 & 12,8 & 14,9 \\
\hline Construcción & 0,6 & 0,6 & 0,6 & 0,6 & 0,6 & 0,8 \\
\hline Transporte & 2,5 & 2,5 & 2,5 & 2,5 & 3,3 & 2,7 \\
\hline Comercio & 16,7 & 16,9 & 16,7 & 16,9 & 16,8 & 19,3 \\
\hline Gobierno & $4,2^{\mathrm{b}}$ & 7,4 & 6,8 & 11,2 & 8,9 & 7,2 \\
\hline Otros & 1,1 & - & - & - & 13,1 & 12,9 \\
\hline
\end{tabular}

Fuente: Coatsworth (1989, cuadros 4 y 5).

a Incluye ganadería, silvicultura y pesca.

b Excluye remesas fiscales netas al Tesoro español. Los ingresos totales del gobierno, incluidas estas remesas, ascendieron a 7,8\% del ingreso colonial.

\section{La era de declinación de México (1780-1870): obstáculos al desarrollo económico}

Dicha favorable posición de la economía mexicana comenzó a deteriorarse en las décadas finales del siglo XVIII. Y si bien puede haber debate respecto al momento en que comenzó ese deterioro, hay consenso en que la independencia en nada contribuyó a impedir el estancamiento de la economía mexicana durante más de la mitad del siglo siguiente. En efecto, entre 1800 y alrededor de 1860 — cuando Estados Unidos y otras economías desarrolladas exhibían tasas de desarrollo económico sin precedentes- el PIB total de México cayó $5 \%$ y su ingreso per cápita se redujo en $30 \%$. Entre 1820 y 1870 , el ingreso per cápita mexicano descendió, como proporción del de los Estados Unidos, de 60\% a 28\%, y desde entonces ha oscilado entre $24 \%$ y $33 \%$ (cuadro 2 ).

¿A qué se debe que la independencia y el surgimiento de un Estado nacional no hayan servido de mayor estímulo al desarrollo económico? Tal vez la razón más importante haya sido el prolongado período de inestabilidad política y el permanente conflicto entre los elementos conservadores y liberales. ${ }^{3}$ Medio

\footnotetext{
${ }^{3}$ En los 55 años transcurridos entre la independencia y el porfiriato, la presidencia cambió 75 veces de mano (Haber, 1989). La consecuencia más desastrosa de la prolongada lucha civil fue la pérdida de la mitad del territorio nacional a manos de los Estados Unidos a mediados del siglo XIX. Cincuenta años después del Tratado de 1848, que puso término a la guerra mexicano-estadounidense, y también tras el comienzo de la "fiebre del oro" en California, la sola producción minera de los territorios perdidos superaba al PIB mexicano (Coatsworth, 1978).
}

siglo de guerras civiles e internacionales terminaron por destruir los efectos potencialmente beneficiosos de la independencia, al mismo tiempo que mermaron los recursos necesarios para que el Estado y el sector privado apuntalaran la reactivación del sector minero y mejoraran la infraestructura de transportes, en un país donde la falta de medios naturales de comunicación y el elevado costo del transporte consiguiente influyeron de manera muy adversa en la división del trabajo y la especialización regional (Coatsworth, 1990).

La independencia eliminó la carga fiscal que pesaba sobre el oro y la plata extraídos de la colonia. Esta carga había sido significativa - Coatsworth (1990) estima que fue $7,2 \%$ de la producción total en 1800-, muy superior, por ejemplo, a la impuesta por el colonialismo británico sobre sus colonias norteamericanas. Sin embargo, el fin del dominio español también trajo consigo algunos costos inesperados para el sector minero, que en parte contrarrestaron la eliminación de esa carga. ${ }^{4}$ Como consecuencia de ello, entre 1812 y 1822 la producción de plata se redujo a menos de la quinta parte del total y el sector minero no vino a recuperar el nivel de producción anterior a la independencia hasta el decenio de 1860 (Cárdenas, 1985). Por su parte, la caída de la producción de plata tuvo otras consecuen-

\footnotetext{
${ }^{4}$ Las guerras de la independencia no sólo tuvieron efectos altamente perturbadores para la producción minera, sino que involucraron también la pérdida del abastecimiento seguro y a bajo costo de mercurio (esencial para la elaboración de minerales de baja ley), que España había proporcionado desde su gran mina en Almadena.
} 
CUADRO 2

México: Producto interno bruto total, producto interno bruto per cápita y población, 1820-1998

\begin{tabular}{|c|c|c|c|c|c|c|c|}
\hline & 1820 & 1870 & 1913 & 1950 & 1973 & 1990 & 1998 \\
\hline PIB per cápita a & 759 & 674 & 1,732 & 2,365 & 4,845 & 6,097 & 6,655 \\
\hline \multirow[t]{2}{*}{ PIB de México/PIB de los Estados Unidos } & 0,60 & 0,28 & 0,33 & 0,25 & 0,25 & 0,26 & 0,24 \\
\hline & & $1820-1870$ & $1870-1913$ & $1913-1950$ & $1950-1973$ & $1973-1998$ & \\
\hline Tasas de crecimiento $(\%)$ del PIB per cápita & & $-0,2$ & 2,2 & 0,9 & 3,2 & 1,3 & \\
\hline Tasas de crecimiento del PIB (\%) & & 0,4 & 3,4 & 2,6 & 6,4 & 3,5 & \\
\hline Tasas de crecimiento de la población (\%) & & 0,7 & 1,1 & 1,8 & 3,1 & 2,2 & \\
\hline
\end{tabular}

Fuente: Maddison (2001).

a Dólares a valores internacionales de 1990.

cias importantes para la economía. Además de la contracción de todas las actividades vinculadas con el sector minero, implicó una merma del volumen del comercio internacional y la disminución de los medios de pago disponibles en la economía nacional (Cárdenas, 1985). Esto último contribuyó a agravar los efectos de la salida de capitales que se produjo tras el éxodo de los mineros y comerciantes españoles y, en consecuencia, la escasez general de capital financiero que caracterizó a este período hasta que se crearon los primeros bancos comerciales en el decenio de 1860.

La eliminación de las restricciones al comercio exterior también resultó ser una bendición a medias. Si bien es cierto que los historiadores económicos generalmente consideran que fue beneficiosa para la economía mexicana, el término de las restricciones al comercio aceleró la desviación del comercio exterior mexicano desde España hacia las potencias industrializadas emergentes del Atlántico norte, tendencia que fue muy perjudicial para el sector manufacturero nacional $\mathrm{y}$, por lo tanto, para la principal actividad que podría haber compensado la decadencia del sector minero. Al respecto, varios estudios han ilustrado de qué manera a fines del siglo la exposición a la competencia de Estados Unidos y Gran Bretaña llevó al colapso de la industria lanera y a la prolongada caída de los textiles de algodón a lo largo de la primera mitad del siglo XIX. Al parecer, la apertura del comercio a la economía del Atlántico y a la competencia externa — que de hecho comenzó durante el período de "comercio libre" y "comercio neutral" introducido por las reformas de los Borbones- también contribuyó a profundizar la fragmentación de los mercados locales y a la división entre un norte minero y agrícola que comerciaba con el resto del mundo, por un lado, y un centro manufac- turero y un sur agrícola sumidos en la depresión económica, por el otro (Thomson, 1986).

Además, poco se avanzó en otras áreas. México en la época colonial había sido uno de los lugares del mundo que exhibía mayores diferencias sociales y regionales; en rigor, una sociedad de castas, en que el acceso al empleo y la movilidad geográfica y ocupacional dependían de distinciones étnicas, y en que una serie de arreglos institucionales tendieron a aumentar, más que a reducir, el abismo entre los beneficios privados y sociales de la actividad económica. Si bien es cierto que la independencia trajo consigo algunos cambios, ${ }^{5}$ muchos de ellos tuvieron escasos efectos en un orden social y político regresivo. En definitiva, es posible que esto haya obedecido a la naturaleza misma del acto fundacional del Estado posterior a la independencia, esto es, al hecho de que tras haberse iniciado y ser derrotado como una insurrección popular - temida por las élites conservadoras españolas y criollas- México finalmente obtuvo la independencia mediante un virtual golpe de Estado de la élite colonial criolla, que tuvo por objeto más que nada apartar al país del proceso liberalizador que tenía lugar en la madre patria (Coatsworth, 1978).

\footnotetext{
${ }^{5}$ Se abolieron oficialmente las distinciones étnicas en el acceso al empleo, a la justicia y en el trato fiscal que, entre otras cosas, habían limitado severamente la movilidad del capital y de la mano de obra; se eliminaron muchos privilegios de los que disfrutaban las empresas así como la mayoría de los gremios, y los derechos de propiedad sobre las empresas se limitaron a la Iglesia, las comunidades indígenas y los municipios. Se redujo el número de monopolios reales sobre la producción y distribución de muchos productos básicos y se regularon sus actividades. Asimismo, se intentó modernizar el sistema judicial y reformar los códigos obsoletos.
} 
Lo anterior tuvo varias consecuencias. Desde luego, de hecho y a veces de derecho, la modernización institucional se desarrolló con lentitud. Recién en 1870 — casi 50 años después de la independencia- se promulgó un nuevo código civil, y aun entonces nada se hizo por reemplazar un código de comercio que era objeto de rechazo. El código de minería de la época se mantuvo prácticamente intacto hasta 1877 . No había legislación bancaria ni de patentes. Y pese a las normas constitucionales se mantuvieron los impuestos y las restricciones al comercio interno.

El sistema de gobierno conservó la arbitrariedad del poder político de la época colonial. El éxito o el fracaso económicos dependían estrictamente de la relación entre la empresa y las autoridades políticas (Coatsworth, 1978, p. 94). En resumen, pese a que la economía continuó centrándose en el Estado, pues todas las empresas estaban obligadas a operar en forma altamente politizada, comparado con la época colonial, el Estado se había debilitado y fue incapaz de eliminar los obstáculos al desarrollo económico derivados de la disminución de la actividad minera, la competencia externa y la falta de infraestructura de transportes y de capital financiero. Así pues, el estancamiento económico e industrial fue consecuencia de la sostenida falta de mercados y de su fragmentación.

\section{2. ¿Errores de percepción liberales a mediados del siglo XIX?}

La anterior lista de obstáculos con que tropezó el desarrollo económico mexicano en el siglo XIX es tan importante por lo que incluye como por lo que deja fuera. La verdad es que estudios realizados por historiadores económicos indican que el sistema de tenencia de la tierra y el poder económico de la Iglesia no se cuentan, como tradicionalmente se cree, entre las causas principales del estancamiento económico de la época.

Desde el siglo XVII, el sistema de tenencia de la tierra y la producción agrícola se habían organizado en torno a grandes haciendas. Pese a ser extremadamente inequitativo, y en este sentido ineficiente desde el punto de vista social y macroeconómico, el sistema de haciendas distaba mucho de ser una organización semifeudal que estimulara el derroche y la mala asignación de los recursos. Investigaciones recientes han puesto de manifiesto una nueva imagen de la hacienda como empresa capitalista y dinámica desde el punto de vista tecnológico, cuya racionalidad económica puede compararse con la de las empresas agrícolas mo- dernas, y que aprovechaba ampliamente sus ventajas comparativas - economías de escala y acceso al crédito externo y a información sobre tecnologías nuevas y mercados lejanos. ${ }^{6}$ En realidad, con el tiempo se estableció una "división del trabajo" entre la hacienda y otras formas de producción agrícola - pequeños propietarios, inquilinos o habitantes de poblados indígenas- en virtud de la cual cada uno de ellos se había especializado en los productos y cultivos en los que tenía una ventaja competitiva: ganado, ovinos, lana, cereales, pulque, azúcar y sisal en las haciendas; y frutas, tomates, ajíes, seda y animales menores como cerdos y aves en el caso de las aldeas y de los productores en pequeña escala.

Un revisionismo similar puede aplicarse a la Iglesia como institución económica. Hacia mediados del siglo XIX, la Iglesia se había convertido en la principal propietaria de tierras del país y en importante prestamista en los mercados financieros emergentes. En cuanto a su primera función, según Coatsworth (1978 y 1990), varios estudios indican que las haciendas pertenecientes a la Iglesia eran administradas al menos con igual eficiencia que las haciendas privadas. En todo caso, después de la independencia, la mayoría de esas propiedades fueron dadas en arrendamiento a agricultores y hacendados privados, de modo que su eficiencia ya no dependía de la gestión eclesiástica. Por otra parte, la Iglesia cobraba el diezmo, un impuesto de $10 \%$ sobre la producción total (que gravaba principalmente la producción agrícola y ganadera). Tal como cualquier otro impuesto, el diezmo reducía la rentabilidad agrícola y probablemente desincentivaba la producción (aunque algunos autores tienen dudas al respecto). ${ }^{7}$ Más importante, sin embargo, fue el uso que se le dio a esos ingresos. Lejos de destinarse a financiar gastos totalmente "improductivos", la Iglesia invirtió parte considerable de sus entradas (incluidos donaciones privadas y los ingresos netos de sus diversas propiedades) en préstamos a empresarios privados, sin imponer restricciones legales o prácticas que impidieran a los beneficiarios invertir los recursos en

\footnotetext{
${ }^{6}$ Véase, entre otros, Van Young (1981 y 1986).

7 Véase, en especial, Garcia Alba (1974) y Coatsworth (1978). Es probable que el diezmo no haya contribuido demasiado a desplazar capitales y mano de obra de la agricultura privada, porque la propia Iglesia y las aldeas indígenas producían parte importante de los productos agrícolas y el ganado del país. En todo caso, lo más probable es que su efecto en el PIB haya sido positivo, puesto que las diferencias de productividad entre la agricultura privada y el resto de la economía sugieren que las actividades no agrícolas ya eran más productivas que la agricultura.
} 
fábricas y no en haciendas u otras actividades. Lo hizo cobrando tasas de interés inferiores a las de mercado, generalmente un $6 \%$ sobre los préstamos garantizados por bienes raíces. Dado el dominio de la Iglesia en el mercado de créditos hipotecarios, es posible que esto haya contribuido a su vez a la baja de las tasas de interés del mercado. Como dice Coatsworth (1978), la Iglesia actuó como un banco de desarrollo moderno, elevando la tasa de acumulación de capital por encima de la que habría sido de no haber existido el diezmo.

De ser correcto el revisionismo de los historiadores económicos, quiere decir que desde el punto de vista estricto (y reconocidamente estrecho) del desarrollo económico, algunos de los elementos principales del programa económico liberal - comercio libre, privatización de la propiedad corporativa y pública y liberalización del mercado agrario- estuvieron muy mal concebidos. Es probable que el primero de ellos, el libre comercio, haya estimulado aún más la caída de la industria manufacturera local y la "ruralización" de la fuerza de trabajo, ya que la expansión de los ferrocarriles a fines del siglo XIX redujo marcadamente la protección natural que proporcionaban los costos tradicionalmente altos del transporte. Como resultado del segundo - la privatización de la propiedad de las empresas - se destruyó la principal y durante mucho tiempo casi la única institución bancaria de la economía. Por su parte, el tercero, la liberalización del mercado agrario contribuiría a concentrar aún más la pro- piedad agrícola y, con el tiempo, a la explosión social que se produjo en 1910.

Lo anterior no quiere decir que la facción conservadora fuera mejor. Si bien es cierto que algunos de sus integrantes, en especial Lucas Alaman, tuvieron el mérito de realizar los primeros y breves intentos de industrialización en el decenio de 1830 mediante la protección de la industria y la creación del primer banco público de desarrollo (el Banco de Avío) para financiar el desarrollo de la industria textil, ${ }^{8}$ las fuerzas sociales y políticas que los apoyaban tendieron a perpetuar ese mismo centralismo extremadamente arbitrario del poder político, que había tenido efectos tan perniciosos en el desarrollo económico desde la época de la colonia.

Como resultado, no surgió la coalición que habría podido forjar un Estado en desarrollo y en su ausencia subsistieron algunos de los principales obstáculos al desarrollo económico. Además, los liberales, que podían y querían emprender la modernización política y social del país, eran también antiestatistas recalcitrantes desde el punto de vista económico, mientras que los únicos partidarios de modernizar la economía mediante la intervención del Estado eran los conservadores, fuertemente contrarios a la modernización política y social. Se requeriría una explosión social y una revolución popular a principios del siglo XX para llevar ambos requisitos del desarrollo económico a una relación menos conflictiva.

\section{III}

\section{El traumático surgimiento de un Estado en desarrollo gershenkroniano}

\section{El porfiriato: la estabilidad política y el surgi- miento de un mercado nacional unificado}

En la práctica, el crecimiento económico moderno se inició a fines del siglo XIX. ${ }^{9}$ En $1895,72 \%$ de la población vivía en zonas rurales y más de $80 \%$ de las personas de 10 años o más no sabían leer ni escribir (cuadro 3). En 1877, cuando Porfirio Díaz se apoderó del poder, las actividades agrícolas generaban $42 \%$ del PIB mexicano, y las manufacturas sólo $16 \%$ (véase el cuadro 1). En los dos decenios siguientes comenzó a quedar de manifiesto un vuelco en el prolongado período de declinación del país. Las barreras a la reactivación económica fueron derribadas por la transformación del entorno económico internacional y por los cambios internos de la estructura política y económica de México introducidos en la dictadura de Porfirio Díaz, período de 33 años de estabilidad política (18771910), que los historiadores mexicanos han denominado con razón el porfiriato.

\footnotetext{
${ }^{8}$ Otro personaje que cabe mencionar es Estevan de Antuñano, industrial criollo cuyos numerosos panfletos aportaban los mejores argumentos en favor del proteccionismo y la industrialización.

${ }^{9}$ Para estadísticas del crecimiento económico durante el porfiriato, véase Beatty (2001), Rosenzweig (1965) y Solis (2000).
} 
México: Población e indicadores sociales, 1895-2000

\begin{tabular}{|c|c|c|c|c|c|}
\hline Año & $\begin{array}{l}\text { Población total } \\
\text { (millones) }\end{array}$ & $\begin{array}{l}\text { Población rural } \\
\text { (porcentaje) }\end{array}$ & $\begin{array}{l}\text { Esperanza de vida al nacer } \\
\text { (años) }\end{array}$ & $\begin{array}{l}\text { Alfabetización }{ }^{\mathrm{a}} \\
\text { (porcentaje) }\end{array}$ & $\begin{array}{l}\text { Promedio años } \\
\text { escolaridad }^{\mathrm{b}}\end{array}$ \\
\hline 1895 & 12,6 & 72 & 30 & $17,9^{\mathrm{c}}$ & $\ldots$ \\
\hline 1910 & 15,2 & $\ldots$ & $\ldots$ & 27,7 & $\ldots$ \\
\hline 1930 & 16,6 & 66,5 & 33,9 & 38,5 & $\ldots$ \\
\hline 1940 & 19,7 & 64,9 & 38,8 & 41,8 & 2,6 \\
\hline 1980 & 68,3 & 33,7 & 66,2 & $83,0^{\mathrm{c}}$ & 4,6 \\
\hline 1990 & 81,2 & 28,7 & 70,8 & 8,4 & 6,6 \\
\hline 1995 & 91,2 & 26,5 & 73,6 & 89,4 & 7,2 \\
\hline 2000 & 97,0 & 25,4 & 75,3 & $90,3^{\mathrm{b}}$ & 7,6 \\
\hline
\end{tabular}

Fuente: Maddison (1989) e INEGI (varios años).

a Población de 10 años o más.

b 15 años o más.

c 6 años o más.

La ideología del porfiriato, que combinaba antecedentes políticos liberales con metas económicas conservadoras, se resume en la consigna positivista Orden y Progreso. Se consideraba que el orden era un elemento indispensable del crecimiento económico. Poner fin a las luchas políticas y militares que habían azotado a México desde la independencia era considerado requisito esencial de la confianza comercial y de la reactivación de la inversión privada. Se procuró con éxito fortalecer el gobierno central, y la combinación del uso de la fuerza y las alianzas con grupos importantes permitieron que Díaz dominara la estructura política.

Por su parte, Progreso significaba transformar a México en una nación industrializada, logrando eliminar algunas de las barreras tradicionales que impedían la reactivación económica, tales como la falta de infraestructura de transporte y de capital financiero. ${ }^{10}$ Para estimular la expansión de la red ferroviaria, el Estado otorgó concesiones e incentivos financieros. Los subsidios a la construcción de vías férreas alcanzaron a un $50 \%$ de su costo total. La ampliación del sistema ferroviario aumentó enormemente el tamaño del mercado, derribó las barreras locales y regionales al comercio y acrecentó la competencia. ${ }^{11}$ Este efecto

\footnotetext{
${ }^{10}$ En esa época, ya se reconocía la importancia de estos obstáculos al desarrollo económico. Como dice Matías Romero, esta nación posee en su suelo enormes tesoros de riqueza agrícola y minera que no pueden explotarse por falta de capital y de comunicaciones (citado por Rosenzweig, 1965).

${ }^{11}$ El sistema ferroviario aumentó de 900 a $19.000 \mathrm{~km}$ en el decenio de 1880. Según estimaciones de Coatsworth, esto redujo en $80 \%$ el costo del flete por kilómetro entre 1878 y 1910.
}

se vio fortalecido por el significativo aumento de la seguridad de los viajes por carretera logrado por el régimen de Díaz.

Otro aspecto clave de la estrategia de desarrollo aplicada por Díaz fue la inversión externa, estimulada activamente después mediante diversos incentivos. Gracias a éstos y a las posibilidades de realizar inversiones rentables se produjo una afluencia de capitales externos. A partir de 1880 entraron capitales estadounidenses, seguidos luego de inversiones europeas (Coatsworth, 1989). Estos flujos de capitales aumentaron sostenidamente los 15 años siguientes, y tuvieron su auge en el primer decenio de 1900 (King, 1970). En líneas más generales, la política pública se orientó a fomentar la inversión privada y a garantizar las condiciones para su buen funcionamiento. Pronto se modificó el marco jurídico para la realización de los negocios privados. Con miras a mejorar las condiciones de la inversión privada, en 1883 se promulgaron nuevos códigos de comercio y de minería. Se eliminaron los impuestos regionales al comercio interno. La política comercial combinó la protección de aranceles específicos compatibles con la industrialización en el sector de bienes de consumo, y la disminución de los aranceles medios que mejoraba el acceso de los fabricantes a capital de bajo costo y a bienes intermedios (Beatty, 2002; Kuntz Ficker, 2002).

La inversión externa significaba acceso a los mercados mundiales, y entre 1870 y 1913 en México se triplicaron las exportaciones como proporción del PIB. La expansión del comercio exterior también contribuyó a aumentar los recursos de que disponía el gobierno, ya que los impuestos que lo gravaban representaban más 
de la mitad de los ingresos públicos. Tal como lo había sido en el período colonial, el sector exportador se convirtió en motor del crecimiento, ayudado en gran medida por la depreciación de la plata a fines del siglo XIX. ${ }^{12}$ En esa oportunidad, la canasta de exportaciones fue bastante más diversificada que en el período colonial, puesto que además de la plata incluía otros minerales - metales industriales como cobre, plomo y zinc, cuya demanda desde los centros industriales de la economía mundial aumentaba rápidamente- y una serie de productos agropecuarios (café, ganado y otros que se agregaron a algunos que ya tenían cierta importancia en la composición de las exportaciones, como henequén, pieles y madera). Estos cambios y reacciones de la política se acompañaron de un entorno económico externo más propicio. Hacia 1870, la segunda revolución industrial de los países industrializados había estimulado la demanda de minerales y otros recursos naturales. Unido al término de la inestabilidad política, este nuevo ambiente ayudó a restablecer la solvencia internacional. ${ }^{13}$

¿Cuáles fueron los resultados generales de esta estrategia? El crecimiento económico y la modernización se dejaron sentir en muchos campos, revirtiendo un siglo de decadencia, y entre 1877 y 1910 el PIB per cápita de México registró un incremento anual medio de 2,1\% (cuadro 2). ${ }^{14}$ La expansión de los ferrocarriles favoreció a algunas actividades tradicionales como la minería, ${ }^{15}$ y al mismo tiempo contribuyó a crear actividades nuevas cuya escala de producción y densidad de capital las hacía poco rentables, a menos que

\footnotetext{
${ }^{12}$ La depreciación de la plata se debió a que hacia 1870 los países avanzados adoptaron el patrón oro (Cárdenas y Manns, 1989). Significó una devaluación real sostenida de $26 \%$ del peso mexicano hasta el decenio de 1890. Véase Zabludovsky (1984), quien evalúa tanto el punto de vista de Rosenzweig (1965) y Nugent (1973) de que la devaluación estimuló el crecimiento impulsado por las exportaciones, como el punto de vista basado en la paridad del poder adquisitivo que sostenía Limantour, ministro de Hacienda de Porfirio Díaz: que, en definitiva, la depreciación de la plata se reflejó en los precios. La evaluación de la evidencia que hace Zabludovsky (1994) favorece el primer punto de vista.

13 Tras haber dejado de cumplir con el pago de su deuda externa en seis oportunidades diferentes entre 1824 y 1880, en 1889 el gobierno mexicano y la banca internacional finalmente llegaron a un acuerdo para renegociar la deuda externa del país. A principios del decenio de 1890 se restableció el acceso de México a los mercados internacionales de capital, y desde esa fecha hasta 1911, la deuda externa mexicana aumentó en $300 \%$, sobre todo con el propósito de financiar obras públicas en infraestructura.

14 Véase Bortz y Haber (2002).

${ }^{15}$ Lo más probable es que de no ser por la expansión ferroviaria la minería habría quedado abandonada, ya que ni los insumos de capital para su desarrollo ni la comercialización de productos minerales habrían sido rentables.
}

existiera un mercado nacional unificado. En rigor, subyacía a este proceso de modernización la primera etapa de la industrialización mexicana en gran escala. Gracias a la sustitución de importaciones de textiles, cerveza, papel, cemento y acero, la producción industrial aumentó un promedio de 3,6\% al año entre 1877 y 1910 (Coatsworth, 1989). Las manufacturas dejaron de ser una actividad artesanal, realizada en pequeñas empresas, para transformarse en un proceso productivo llevado a cabo en grandes fábricas. Al mismo tiempo, se modificó profundamente la estructura social y económica de las zonas rurales. A partir de un diagnóstico de que el sector rural era improductivo y que la mayor parte de la producción agrícola se distribuía por conductos distintos del mercado, el gobierno de Díaz promovió y aceleró la redistribución de las tierras de propiedad federal y comunal a empresas de desarrollo privadas y a particulares acaudalados. La privatización habría de fomentar los cultivos comerciales en gran escala. En 1890, el 20\% del territorio mexicano pertenecía a menos de 50 personas o empresas. Hacia principios de la década de 1900, el $95 \%$ de la tierra cultivable pertenecía a 835 familias (Manzanilla Schaffer, 1963).

Hacia principios del decenio de 1900, este patrón de desarrollo comenzó a mostrar síntomas de agotamiento. A partir de 1903, los salarios reales empezaron a caer sistemática y sostenidamente. En 1907, la sequía redujo la producción de alimentos y contribuyó a elevar aún más su precio. En 1910, la caída acumulada de los salarios reales fue de $26 \%$ en comparación con 1903. Aunque la hambruna no era manifiesta, la pobreza era generalizada, especialmente en las zonas rurales. ${ }^{16} \mathrm{Al}$ mismo tiempo, el uso de la fuerza para reprimir a los trabajadores y sofocar la oposición política se tornó más frecuente y, a la larga, infructuoso. En 1910, la desigual distribución de los beneficios y del acceso al poder llegó a su límite. Las clases medias emergentes excluidas de las decisiones políticas, y los trabajadores y campesinos marginados de los beneficios del crecimiento económico, lograron unirse en torno a una coalición que venció bajo las consignas de democracia política, reforma agraria y derechos laborales.

\footnotetext{
${ }^{16}$ Como lo destaca Haber (1989), tal era el grado de pobreza, que si aumentaba el precio del maíz a causa de una mala cosecha, el consumo de manufacturas de los trabajadores disminuiría lo suficiente como para provocar una crisis en la industria de prendas de algodón.
} 
¿Qué había salido mal? No hay duda alguna de que la "contradicción básica" del porfiriato se dio en sus resultados: el desequilibrio creciente entre un crecimiento económico acelerado, por un lado, y la lentitud de los avances políticos y sociales, por el otro. Porfirio Díaz se propuso hacer de México una nación industrializada moderna. Sin embargo, en 1910 sólo $28 \%$ de los mexicanos sabía leer y escribir y la esperanza de vida al nacer no superaba los 37 años. Con dos tercios de su población viviendo aún en zonas rurales, México continuaba siendo más que nada una economía estacionaria y, en general, una sociedad atrasada. Además, pese a que el surgimiento de un mercado nacional había derribado algunas de las barreras del estancamiento, el papel del Estado demostró ser insuficiente para superar los aún enormes obstáculos al desarrollo económico. ${ }^{17}$

\section{La revolución y la consolidación del Estado desarrollista}

En 1910, la revolución mexicana puso dramático fin a la pax porfiriana. Una vez más, la falta de consenso social se convirtió en el principal obstáculo para el desarrollo del país. Sólo tres decenios más tarde pudo lograrse un pacto social estable.

Las etapas más violentas de la revolución mexicana terminaron tras la adopción de una nueva Constitución, en 1917. El descontento político se mantuvo durante los diez años siguientes — marcados por la muerte violenta de figuras tan importantes como Zapata, Carranza y Obregón y por numerosos levantamientos-, pero los enfrentamientos armados disminuyeron de manera significativa. La Constitución de 1917 redefinió el marco jurídico de la propiedad de la tierra y las relaciones laborales. Situó a la nación por encima de la propiedad privada cuando se trataba de los recursos de tierra, agua y subsuelo; estableció el derecho a formar sindicatos, creó un sistema de salarios mínimos, de jornadas de trabajo de ocho horas en semanas laborales de seis días, y el derecho a ganar igual salario por tareas equivalentes, e incluyó una reforma agraria mediante la expropiación de los grandes predios y su asignación a los ejidos, sistema de tenencia de la tierra que combinaba la propiedad colectiva con la explotación privada de la tierra.

${ }^{17}$ La inversión pública nunca superó el 5\% de la inversión total, y sólo $7 \%$ del gasto público se destinó a la acumulación de capital.
Con la creación del Partido Nacional Revolucionario (PNR) en $1929^{18}$ se dio un paso fundamental para consolidar la paz social y la estabilidad política. Este partido oficial, que pasó a llamarse Partido de la Revolución Mexicana (PRM) en 1938 y Partido Revolucionario Institucional (PRI) en 1946, abarcó todas las fuerzas sociales importantes de la revolución mexicana y pronto se transformó en vehículo funcional de control del poder político y único campo legítimo donde resolver las diferencias políticas. Hacia el decenio de 1940 se había terminado la era de los caudillos y se había iniciado la forma propiamente mexicana de control autoritario institucionalizado.

Tras la revolución, el proceso de consolidación del poder político se acompañó de la expansión de los mecanismos de política a los que podía recurrir el gobierno. ${ }^{19}$ Bajo la presidencia de Cárdenas (19361940), el sector público se amplió aún más con la creación de varias entidades financieras y de desarrollo. Lo que es más importante, se nacionalizó la industria petrolera y se comenzó a aplicar la reforma agraria en gran escala. La política fiscal se tornó anticíclica y se incurrió en déficit presupuestarios para impulsar la inversión productiva y social. El gasto público se reorientó hacia gastos no militares ni administrativos. El sistema de carreteras se amplió en siete veces, llegando a abarcar $9.900 \mathrm{~km}$ en 1940. Además, la flotación transitoria del tipo de cambio se tradujo en una depreciación del peso en valores reales.

El crecimiento de México se reanudó en el bienio 1933-1934, con el vuelco en la conducción de las políticas de gobierno y la extraordinaria recuperación de la relación de intercambio de la plata y el petróleo (principales exportaciones del país). La primera ronda nueva de inversiones desde el porfiriato se inició en la industria manufacturera y se centró en nuevas actividades textiles. La industria manufacturera pasó a ser el sector más dinámico de la economía.

\footnotetext{
18 Véase en Newell y Rubio (1984) una descripción detallada de la creación del PNR y de su papel en la estabilidad política a largo plazo.

${ }^{19}$ El Banco de México fue creado en 1925 para hacer frente a la depresión y empezó a operar como Banco Central a comienzos de 1930. Hacia entonces se había creado el Banco Nacional de Crédito Agrícola, que fue seguido de otros bancos. En 1933, la Secretaría de Presupuesto creó la Entidad Nacional Financiera, que pronto se transformaría en la Nacional Financiera, primer banco de desarrollo propiamente tal y puntal financiero para la inversión industrial y otras inversiones de largo plazo.
} 


\section{Los años dorados de industrialización de la posguerra (1940-1980)}

En el proceso orientado a lograr la hegemonía, el Estado llegó a la firme convicción de que, para alcanzar el desarrollo, debía participar activamente en la inversión y la producción. Hacia fines del decenio de 1940 controlaba los recursos fundamentales y había aumentado sustancialmente el número de instrumentos de política. La inversión pública aumentó sistemáticamente (cuadro 4) y se canalizó hacia el desarrollo urbano e industrial. Para promover las actividades manufactureras se otorgaron incentivos adicionales, como exenciones tributarias. Los gastos federales incluyeron inversiones en educación y bienestar social. Al mismo tiempo, la campaña industrializadora se acompañó de un aumento de la protección comercial y hacia 1947 el proteccionismo había sido oficialmente adoptado como objetivo intermedio del gobierno.

Entre 1940 y 1980 tuvo lugar una amplia transformación de la economía y de la sociedad. En valores reales, la economía mexicana creció a un ritmo sostenido de 6,4\% anual y el PIB per cápita a razón de $3,2 \%$ al año. La industria manufacturera se convirtió en motor del crecimiento y entre 1945 y 1955 registró tasas de incremento del producto del orden de 7,4\% anual, y aceleró su ritmo de desarrollo entre 1957 y 1970 al expandirse a tasas de $8,9 \%$ al año, gracias al dinamismo del mercado interno que fue su principal fuente de demanda. De país agrario, México se transformó en una sociedad urbana semiindustrial. Entre 1940 y 1980, la participación de la industria manufacturera en el producto se elevó de $15,4 \%$ a $24,9 \%$ (cuadro 5), mientras la proporción de personas que vivía en zonas urbanas aumentó explosivamente de 35\% a $66 \%$ de la población y el total de habitantes del país

CUADRO 4

México: Tasas de inversión, 1900-1980

\begin{tabular}{lcc}
\hline Años & $\begin{array}{c}\text { Inversión } \\
(\% \text { del PIB })\end{array}$ & $\begin{array}{c}\text { Inversión pública } \\
(\% \text { del PIB })\end{array}$ \\
\hline 1900 & 10,1 & $0,5^{\mathrm{a}}$ \\
1910 & 10,1 & 0,4 \\
1921 & 10,1 & $\ldots$ \\
1930 & 9,4 & 2,2 \\
1940 & 9,3 & 3,5 \\
1960 & 17,2 & 5,2 \\
1980 & 24,8 & 11,4 \\
\hline
\end{tabular}

Fuente: CEPAL e INEGI.

a 1895. pasaba de 20 a 70 millones de personas (cuadro 3). Las tasas de alfabetización prácticamente se duplicaron y en 1980 llegaron a 83\%. La escolaridad media de la población adulta se elevó de 2,6 a 7,1 años y la esperanza de vida al nacer aumentó de 24 a 65 años. Sin embargo, pese a estas mejoras, la distribución de los beneficios del crecimiento distaba mucho de ser equitativa. Hacia fines del período, el $20 \%$ de la población percibía más del $50 \%$ del ingreso total disponible, mientras que un 58\% de los mexicanos seguía viviendo en condiciones de pobreza. ${ }^{20}$ En consecuencia, al término de los años dorados, en México aún quedaban por resolver los problemas de pobreza y desigualdad.

El desempeño macroeconómico del período comprendido entre 1940 y 1970 fue ciertamente notable. La estrategia aplicada abordó problemas importantes que dificultaban el desarrollo del país, pero en cambio pasó por alto o subestimó la magnitud de otros obstáculos.

El primero de estos obstáculos fue la poca atención prestada a la agricultura, la que después de 1965 tropezó con serias dificultades para elevar su producción. En la segunda mitad del decenio de 1960 su tasa de crecimiento se situó por debajo de la tasa de expansión demográfica. Entre los factores que explican esta caída se hallan la dicotomía del sector, la tendencia adversa de los precios de los productos agrícolas en comparación con la de los precios de los productos manufacturados, y la baja sostenida de la participación de la agricultura en la inversión pública después del decenio de 1950. Todos estos factores contribuyeron a aumentar la pobreza, a contraer la demanda potencial del mercado interno y a provocar una pérdida de cohesión social que dio lugar a una incipiente inestabilidad social.

En segundo lugar, pese a que en muchos sectores la protección del comercio resultó ser un mecanismo valioso para promover el crecimiento y la sustitución de importaciones, ni el sector privado ni el sector público aplicaron una política destinada expresamente a fortalecer el potencial exportador de la economía. Además, no era claro que la política que se estaba aplicando pudiera completar la etapa más difícil del proceso de sustitución de importaciones, que involucraba la importación de bienes de capital de alta tecnología.

Por último, las reformas tributarias fracasaron sistemáticamente y las finanzas públicas dependieron

\footnotetext{
${ }^{20}$ Estimaciones menos moderadas sitúan esta cifra en $63 \%$ (véase Hernández Laos, 1989).
} 
GRAFICO 1

México. Producto interno bruto, 1921-1997

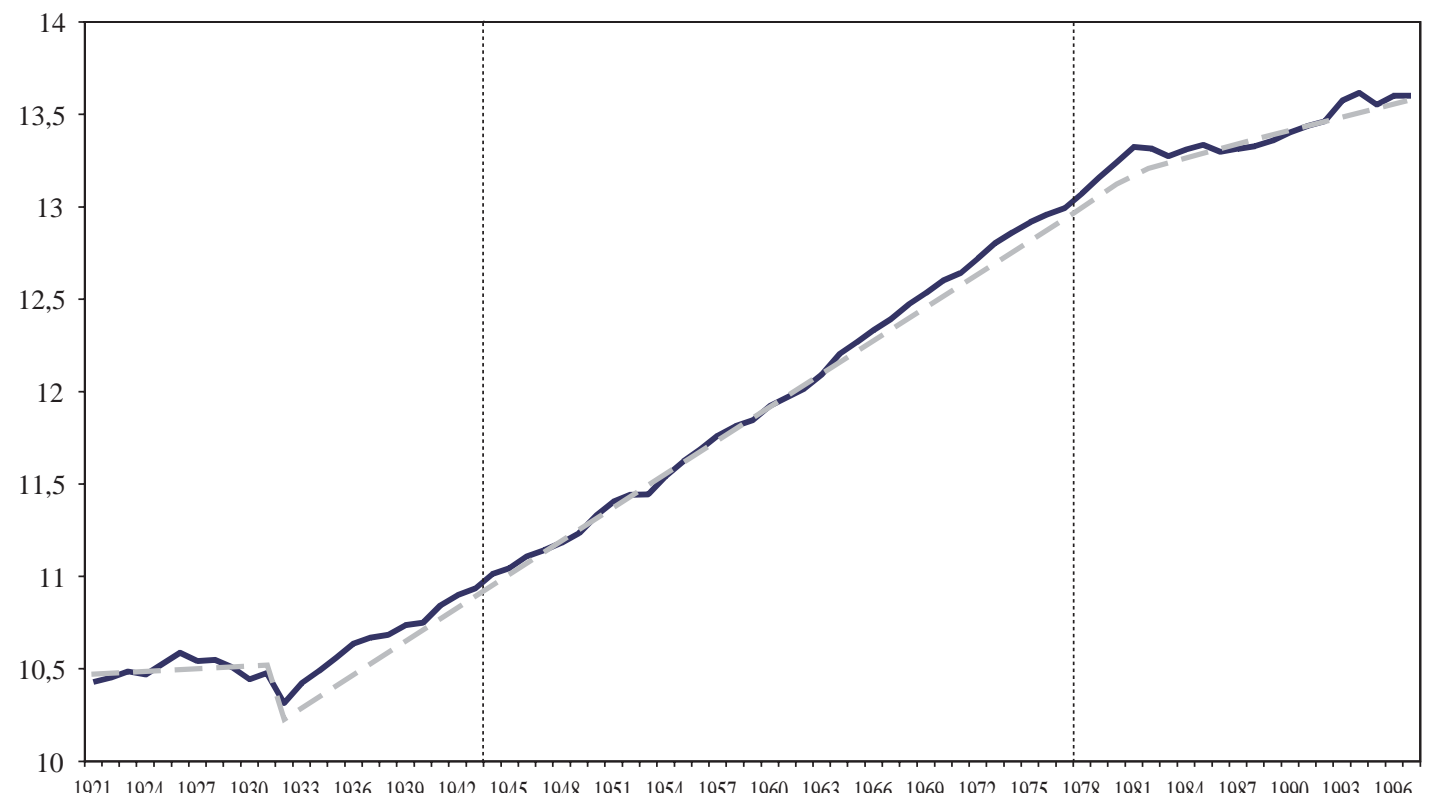

19211924192719301933193619391942194519481951195419571960196319661969197219751978198119841987199019931996

$\longrightarrow \operatorname{Ln}(\mathrm{GDP})--$ Tendencia

Fuente: Solís (2000).

CUADRO 5

México: Estructura del producto interno bruto, 1895-2002

(Porcentajes)

\begin{tabular}{|c|c|c|c|c|c|c|c|c|c|c|c|c|}
\hline & 1885 & 1910 & 1926 & 1932 & 1940 & 1955 & 1970 & 1970 & 1980 & 1980 & 1990 & $2000-2002$ \\
\hline & \multicolumn{7}{|c|}{ A precios de 1960} & \multicolumn{2}{|c|}{ A precios de 1980} & \multicolumn{3}{|c|}{ A precios de 1993} \\
\hline Agricultura $^{\mathrm{a}}$ & 29,1 & 24,0 & 19,7 & 24,1 & 19,4 & 18,3 & 11,6 & 12,2 & 9,0 & 7,1 & 6,7 & 7,6 \\
\hline Minería & 3,0 & 4,9 & 9,3 & 7,2 & 6,4 & 4,8 & 4,8 & 2,5 & 3,3 & 1,4 & 1,5 & 2,1 \\
\hline Industria & 9,0 & 12,3 & 14,7 & 13,3 & 18,7 & 22,1 & 2,7 & 30,1 & 31,9 & 25,0 & 24,1 & 27,0 \\
\hline (Manufactura) & $(7,9)$ & $(10,7)$ & $(11,6)$ & $(10,2)$ & $(15,4)$ & $(17,5)$ & $(23,3)$ & $(23,7)$ & $(24,9)$ & $(19,2)$ & $(19,6)$ & (21) \\
\hline Servicios & 58,9 & 58,7 & 56,3 & 55,4 & 55,5 & 54,7 & 53,9 & 55,2 & 55,8 & 66,5 & 67,6 & 63,3 \\
\hline Total & 100 & 100 & 100 & 100 & 100 & 100 & 100 & 100 & 100 & 100 & 100 & 100 \\
\hline
\end{tabular}

Fuente: Banco de México e INEGI.

a Incluye ganadería, silvicultura y pesca.

cada vez más de la deuda externa. ${ }^{21}$ Otro tanto sucedió con la balanza de pagos, que se tornó cada vez más vulnerable a las corrientes de capital de corto plazo, que pueden ser desestabilizadoras. Mientras continua-

${ }^{21}$ Hacia 1972, tanto la relación deuda/PIB como la relación servicio de la deuda/exportaciones habían llegado a 18\% (comparado con $1 \%$ en 1946). Aunque estas magnitudes no significaban un grave ran los años dorados del crecimiento económico mundial, poco importaba equivocarse sobre la importancia que podrían llegar a tener estos problemas. Por desgracia, los años dorados llegaban a su fin.

desequilibrio macroeconómico, ilustran el dinamismo de la evolución del endeudamiento externo en el período. 


\section{EI "desarrollo compartido", el auge petrolero y la crisis de la deuda}

En la medida en que los gobiernos del decenio de 1970 no superaran estos obstáculos, podían tornarse - y así lo hicieron - perturbadoramente costosos. El argumento central de la plataforma política del gobierno de Echeverría, que asumió el poder a fines del decenio de 1970, fue que la estrategia de "desarrollo estabilizador" aplicada en el período comprendido entre 1956 y 1970 no había logrado resolver el problema fundamental de la desigualdad. Se propuso entonces una nueva estrategia, de "desarrollo compartido", en virtud de la cual los beneficios del crecimiento económico se distribuirían más equitativamente. En la práctica, sin embargo, las políticas adoptadas no lograrían ese objetivo.

Durante un tiempo, dicha estrategia efectivamente produjo el efecto deseado en la distribución funcional del ingreso. Gil Diaz (1987) muestra que la participación de la mano de obra en el producto nacional neto aumentó de $40 \%$ en 1970 a $43 \%$ en el período 19721974, y llegó a 49\% en 1976. Además, el PIB logró un crecimiento anual medio de 6,1\%. Desafortunadamente, estos logros se acompañaron de serios desequilibrios macroeconómicos.

Esto se debería a varias razones. En el ámbito externo, el colapso de los años dorados en el mundo se dejó sentir en la economía mexicana. La primera crisis de los precios del petróleo, que ocurrió siendo México importador neto de crudo, y también la caída de la demanda externa, acrecentaron las restricciones de balanza de pagos sobre el crecimiento. Además, entre 1970 y 1975 el incremento de las tasas de inflación internas hasta alrededor de $20 \%$, la expansión de las inversiones públicas y el tipo de cambio fijo triplicaron el déficit comercial. Por otra parte, el modelo de industrialización empezó a dar señales de agotamiento. Pese a las inversiones para modernizar las plantas en los sectores ya expuestos a la competencia externa, éstas no aumentaron significativamente las exportaciones ni acentuaron la sustitución de importaciones en el sector de bienes de capital. Debido a que no se realizó una reforma tributaria, los ingresos públicos se rezagaron. Entre 1971 y 1976 el déficit fiscal se elevó de 2,5\% a 9,9\% del PIB y se solventó cada vez más mediante la expansión monetaria y la deuda externa (que se elevó a una tasa anual media de $40 \%$ entre 1973 y 1976). ${ }^{22}$ Cabe agregar que el sector pri-

22 En esa época, los economistas tradicionales criticaron con toda razón la idea de que era posible acelerar el desarrollo, en especial vado no encontró terreno fértil en la retórica del "desarrollo compartido" y muy pronto la expansión de la economía era impulsada exclusivamente por el gasto público. Con el tiempo, la fuga de capitales agravó sustancialmente la situación. Pese al aumento del control sobre las importaciones y a la aplicación de aranceles, en 1976 las presiones sobre la balanza de pagos obligaron al gobierno a depreciar el peso casi en $100 \%$, abandonando así una paridad cambiaria que no había variado a lo largo de más de 20 años.

No obstante la gravedad de la crisis de 1976, al cabo de poco más de un año las perspectivas económicas de México dieron un vuelco, al anunciarse que el país tenía grandes reservas de petróleo. Su explotación y venta en los mercados internacionales traerían consigo una rápida y vigorosa reactivación. Una vez más se pudo controlar el déficit comercial, que se situó en un promedio de 1,5\% del PIB. Se renegociaron los plazos de la deuda externa y, durante algún tiempo, el endeudamiento no aumentó en forma significativa. Se inició un ambicioso plan de industrialización en el supuesto de que los precios del petróleo seguirían aumentando. Las inversiones en la industria manufacturera se elevaron sustancialmente, impulsadas por las empresas públicas y privadas, y entre 1978 y 1981 el PIB creció a tasas anuales de $8 \%$ a 9\%. Asimismo, en este período se introdujo una importante reforma tributaria y los cambios redujeron en alguna medida las inequidades del sistema tributario mexicano. ${ }^{23}$

Sin embargo, en retrospectiva, hacia fines de la década de 1970 había ya algunas señales inquietantes. La inflación se había estabilizado en torno al $18 \%$ y nada indicaba que fuese a bajar. Los pagos por concepto de intereses iban en aumento al elevarse de manera sin precedente las tasas de interés nominales en los mercados de crédito internacionales. La inversión en el sector exportador fue escasa, salvo en dos casos: la industria automotriz, en la que se estaba construyendo una nueva serie de plantas dotadas de la más

el desarrollo social, sacrificando la disciplina fiscal. Véase en Solís (1977) una convincente exposición al respecto.

${ }^{23}$ Se introdujo un ajuste por concepto de impuesto a la renta y se establecieron un impuesto al valor agregado y un impuesto sobre las utilidades de las empresas. Asimismo, se amplió la base tributaria al eliminarse los resquicios legales y se simplificó el proceso administrativo y de fiscalización del cumplimiento de las obligaciones. La contribución del tramo de uno a cinco salarios mínimos pasó de $58 \%$ de lo recaudado por concepto de ingreso de la mano de obra en 1975 , a $28 \%$ en 1981. Por su parte, el tramo de salarios más altos —más de 15 salarios mínimos- se elevó de $8 \%$ a $25 \%$ del total. Véase una descripción detallada en Gil Diaz (1987). 
moderna tecnología con el expreso objetivo de competir en los mercados mundiales, y la industria petroquímica, en la que el sector público realizaba grandes inversiones.

\section{IV}

\section{El giro de la relación mercado-Estado desde mediados del decenio de 1980}

En la década de 1980, la economía mexicana experimentó dos grandes perturbaciones de origen externo: en 1982, la crisis de la deuda, que aumentó los pagos por concepto de servicio de la deuda y dificultó la obtención de nuevos créditos externos, y en 1986, la crisis del petróleo, que cortó espectacularmente gran parte de la principal fuente de divisas y de ingresos fiscales del país. Ambas perturbaciones externas pusieron fin al prolongado período de expansión económica acelerada.

A comienzos del decenio de 1990, los déficit fiscales y de divisas a que dieron lugar la crisis de la deuda y la del petróleo pudieron resolverse tras una serie de intentos de estabilización, de corte tradicional y no tradicional. Entretanto - si se nos permite apropiarnos del término que utiliza Polanyi (1944) para referirse a otra clase de sucesos- se había estado produciendo una "gran transformación". La liberalización de la balanza de pagos y el Tratado de Libre Comercio (TLC) de América del Norte integraron estrechamente a la economía mexicana y la estadounidense, tanto en lo que se refiere a comercio como a flujos de capital. Tras la eliminación de las restricciones a la propiedad extranjera, la participación extranjera en la economía ha aumentado mediante inversiones directas en nuevas plantas, además de fusiones y adquisiciones. Salvo raras excepciones, se han privatizado los bancos estatales y las empresas públicas. Los ingresos provenientes de las privatizaciones, unidos al alivio de la carga de la deuda (en virtud del Plan Brady, de 1989) y a los ajustes fiscales, permitieron que el gobierno redujera la deuda, como proporción del PIB, a niveles relativamente bajos de acuerdo con los estándares internacionales. Gracias a cambios profundos en el sistema de tenencia de la tierra, a las políticas de precios y a la privatización o eliminación de las empresas estatales y su reemplazo por una combinación de subsidios y programas públicos, se generó una economía rural orientada al mercado. En resumen, se llevó a cabo un proceso de reformas de amplio alcance a fin de aumentar la función económica del sector privado y dar mayor margen a la acción de las fuerzas de mercado, y de acelerar la inserción en la economía mundial. ${ }^{24}$

\section{Privatización y eficiencia económica}

Los argumentos en pro de una participación más selectiva del Estado en la economía y, de hecho, a favor de que éste se desprenda de una serie de actividades de producción, han sido de orden macroeconómico: el limitado cupo del gobierno en los mercados de crédito, la necesidad de satisfacer demandas sociales apremiantes, así como la existencia de un sector privado con abundantes recursos financieros en el extranjero y dispuesto a invertirlos en el país en actividades de escasa prioridad social que antes estaban principalmente en manos del Estado. A decir verdad, los argumentos son poderosos, pero por consideraciones macroeconómicas relacionadas con la situación especial del decenio de 1980 y que tienen poco que ver con el potencial de crecimiento a largo plazo de la economía, de no ser por la perspectiva (que hasta ahora no pasa de ser una perspectiva) de que aumentaran sustancialmente las inversiones en capital humano gracias a los cuantiosos ingresos generados por las privatizaciones.

Naturalmente, también es posible justificar las privatizaciones por razones microeconómicas más tradicionales, basadas en la idea de que una mayor participación del sector privado traerá consigo un incremento de la eficiencia general de las inversiones. Si esta depende positivamente de la participación de la inversión privada en la inversión global, quiere decir entonces que

\footnotetext{
${ }^{24}$ Véase un estudio detallado del proceso de reformas en Lustig (2002). Cordera y Lomelí (2000) ofrecen un excelente estudio en profundidad del patrón cambiante y del eventual debilitamiento del papel autoritario de los presidentes mexicanos en la formulación y aplicación de la política económica.
} 
se podría compensar parte — si no toda— la caída de la tasa global de acumulación, modificando la composición de la inversión. Como se indica en el cuadro 6, en el decenio de 1980 efectivamente se produjo un giro espectacular en la composición de las inversiones: la participación del sector privado en la inversión total fija pasó de 56\% en 1980-1981, a 76\% diez años después y a $84 \%$ a fines de la década de 1990 .

$\mathrm{Al}$ abordar este tema, hay que comenzar por reconocer que la eficiencia de la inversión global no depende únicamente de su composición pública/privada, sino también de la propia tasa de inversión, que influye en la eficiencia de la inversión mediante sus efectos en la distribución por edades y en la estructura del acervo de capital (domiciliado/no domiciliado, inversión neta/depreciación). Ahora bien, como también lo indica claramente el cuadro 6, la variación en la composición pública/privada de la inversión obedeció a la caída absoluta de la tasa de inversión pública y no al aumento absoluto de la inversión privada: a comien- zos del decenio de 1990, el nivel de esta última, como proporción del PIB, era aproximadamente el mismo de diez años antes y en el período 2001-2002 era sólo 3 ó 4 puntos porcentuales más alta. Por lo tanto, si aumentó la participación de la inversión privada en la inversión total, ello se debió sobre todo al colapso de la inversión pública. A menos que en la práctica la productividad de la inversión pública haya sido negativa - y hasta donde sabemos, nadie lo ha sostenido-, lo más probable es que las pérdidas de eficiencia provocadas por la caída absoluta de la tasa global de inversión contrarresten los aumentos de eficiencia generados por el cambio de su composición. El incremento de la relación capital-producto registrado a partir de 1982 coincide plenamente con esta conclusión.

Por otra parte, no hay duda alguna de que la relación entre la eficiencia y la composición de la inversión global es bastante más compleja de lo que generalmente se supone. Probablemente tenga la forma de una curva de Laffer, en la cual los bajos niveles de

México: Estructura del capital fijo bruto

(Miles de millones de pesos de 1993 y porcentajes)

\begin{tabular}{|c|c|c|c|c|c|c|c|c|c|}
\hline & \multicolumn{9}{|c|}{ Inversión } \\
\hline & \multicolumn{3}{|c|}{ Total } & \multicolumn{3}{|c|}{ Pública } & \multicolumn{3}{|c|}{ Privada } \\
\hline & PIB & $\begin{array}{l}\text { Miles de } \\
\text { millones }\end{array}$ & $\%$ del PIB & $\begin{array}{l}\text { Miles de } \\
\text { millones }\end{array}$ & $\begin{array}{c}\% \text { de la } \\
\text { inversión total }\end{array}$ & $\%$ del PIB & $\begin{array}{l}\text { Miles de } \\
\text { millones }\end{array}$ & $\begin{array}{c}\% \text { de la } \\
\text { inversión total }\end{array}$ & $\%$ del PIB \\
\hline 1980 & 948,6 & 206,3 & 21,8 & 88,8 & 43,0 & 9,4 & 117,5 & 57,0 & 12,4 \\
\hline 1981 & 1029,5 & 239,8 & 23,3 & 108,8 & 45,4 & 10,6 & 131,1 & 54,6 & 12,7 \\
\hline 1982 & 1024,1 & 199,6 & 19,5 & 88,3 & 44,2 & 8,6 & 111,3 & 55,8 & 10,9 \\
\hline 1983 & 988,4 & 143,1 & 14,5 & 56,5 & 39,5 & 5,7 & 86,6 & 60,5 & 8,8 \\
\hline 1984 & 1022,1 & 152,3 & 14,9 & 58,8 & 38,6 & 5,8 & 93,5 & 61,4 & 9,1 \\
\hline 1985 & 1044,5 & 164,3 & 15,7 & 59,3 & 36,1 & 5,7 & 105,0 & 63,9 & 10,0 \\
\hline 1986 & 1012,3 & 144,9 & 14,3 & 50,9 & 35,1 & 5,0 & 94,0 & 64,9 & 9,3 \\
\hline 1987 & 1029,8 & 144,7 & 14,1 & 44,6 & 30,8 & 4,3 & 100,1 & 69,2 & 9,7 \\
\hline 1988 & 1043,0 & 162,5 & 15,6 & 40,6 & 25,0 & 3,9 & 121,9 & 75,0 & 11,7 \\
\hline 1989 & 1085,8 & 171,9 & 15,8 & 43,5 & 25,3 & 4,0 & 128,4 & 74,7 & 11,8 \\
\hline 1990 & 1142,0 & 194,5 & 17,0 & 48,4 & 24,9 & 4,2 & 146,1 & 75,1 & 12,8 \\
\hline 1991 & 1190,1 & 215,8 & 18,1 & 48,7 & 22,6 & 4,1 & 167,2 & 77,4 & 14,0 \\
\hline 1992 & 1232,3 & 239,2 & 19,4 & 47,1 & 19,7 & 3,8 & 192,2 & 80,3 & 15,6 \\
\hline 1993 & 1256,2 & 233,2 & 18,6 & 47,3 & 20,3 & 3,8 & 185,9 & 79,7 & 14,8 \\
\hline 1994 & 1312,2 & 252,7 & 19,3 & 64,9 & 25,7 & 4,9 & 187,9 & 74,3 & 14,3 \\
\hline 1995 & 1230,6 & 179,4 & 14,6 & 44,6 & 24,8 & 3,6 & 134,9 & 75,2 & 11,0 \\
\hline 1996 & 1293,9 & 208,9 & 16,1 & 38,0 & 18,2 & 2,9 & 170,9 & 81,8 & 13,2 \\
\hline 1997 & 1381,5 & 252,8 & 18,3 & 41,8 & 16,5 & 3,0 & 211,0 & 83,5 & 15,3 \\
\hline 1998 & 1449,3 & 278,8 & 19,2 & 38,7 & 13,9 & 2,7 & 240,1 & 86,1 & 16,6 \\
\hline 1999 & 1503,5 & 300,3 & 20,0 & 42,9 & 14,3 & 2,9 & 257,4 & 85,7 & 17,1 \\
\hline 2000 & 1602,3 & 334,4 & 20,9 & 54,5 & 16,3 & 3,4 & 279,9 & 83,7 & 17,5 \\
\hline 2001 & 1597,2 & 314,9 & 19,7 & 47,5 & 15,1 & 3,0 & 267,5 & 84,9 & 16,7 \\
\hline $2002^{\mathrm{a}}$ & 1611,7 & 310,9 & 19,3 & 50,9 & 16,4 & 3,2 & 260,0 & 83,6 & 16,1 \\
\hline
\end{tabular}

Fuente: CEPAL e INEGI.

a Cifras preliminares. 
eficiencia son compatibles a la vez con tasas muy altas o muy bajas de inversión pública. Como sugieren varias investigaciones empíricas recientes, ${ }^{25}$ ello ocurre porque la propia inversión pública influye de manera positiva en la productividad de la inversión privada, de manera que si el nivel de inversión pública es bajo cualesquiera reducciones adicionales pueden producir mermas antes que aumentos de la eficiencia general. Dada la acentuada contracción de la inversión pública que se produjo en la década de 1980 y en vista de que en la mayoría de las empresas recién privatizadas aún no se registran aumentos de la eficiencia macroeconómica ni mejoras en sus resultados, cabe preguntarse si la economía se trasladó hacia el lado equivocado de la curva de Laffer. En tal caso, la mejor forma de resolver el problema de la eficiencia de la inversión es aumentar la inversión pública en áreas de alta rentabilidad social y elevadas externalidades positivas.

\section{Liberalización del comercio, productividad y crecimiento}

Los resultados de la reforma de la política comercial también son debatibles. Examinemos en primer lugar el incremento de la eficiencia estática que prevé la teoría clásica del comercio. ${ }^{26}$ Una de las características notables de la transición mexicana hacia un régimen de libre comercio es la falta de tropiezos de los procesos macroeconómicos de reasignación de los recursos. El hecho de que las tendencias actuales del patrón de comercio y la estructura industrial sean en gran medida una extrapolación del pasado revela la falta de procesos masivos de reasignación de los recursos. Salvo raras excepciones — tales como la expansión acelerada de las exportaciones de maquila con uso intensivo de mano de obra en la década de 1990_ los procesos de reasignación se han desarrollado mediante la extrapolación de la evolución anterior de los patrones industrial y de comercio marcados por la importancia creciente de los bienes intermedios pesados, los

\footnotetext{
25 En la bibliografía relativa al capital público véanse, entre otros, los estudios de Aschauer (1989a, 1989b y 2000), Deno (1988), Munnell (1990), Easterly y Rebelo (1993).

${ }^{26}$ Para un estudio detallado de los procesos de reasignación de los recursos, véase Ros (1992) y, en especial, el estudio realizado por Moreno-Brid (1988) sobre uno de sus aspectos más importantes, esto es, la reestructuración de la industria automotriz y su papel en el auge exportador de manufacturas del decenio de 1980.
}

bienes de consumo duraderos y los bienes de capital. Sin embargo, la contrapartida de esta transición gradual y del hecho que en las actividades manufactureras no se haya invertido la dirección de los cambios estructurales, es que el clásico aumento de la eficiencia que se espera obtener de la liberalización comercial no puede ser demasiado importante. La verdad es que hasta ahora, para quienes esperan una amplia, dolorosa pero favorable reasignación de los recursos en favor de los bienes exportables tradicionales, que hacen uso intensivo de mano de obra y de recursos naturales, la experiencia en materia de liberalización comercial ha sido muy desalentadora.

A nuestro juicio, lo ocurrido obedece a dos factores principales. El primero es que, tal vez paradójicamente, los ajustes a la crisis de la deuda y al deterioro de la relación de intercambio del decenio de 1980, y posteriormente los ajustes a la crisis financiera de 1994-1995, obligaron a la política macroeconómica a entregar niveles sin precedentes de "protección cambiaria" que facilitaron el ajuste de las empresas industriales a una economía más abierta. El segundo consiste simplemente en la satisfactoria experiencia mexicana con la sustitución de importaciones y la avanzada etapa en que se encontraban los procesos de especialización y comercio entre industrias (y entre empresas) en 1980, incluso en las grandes industrias manufactureras con gran densidad de capital que han sido en parte responsables del auge de las exportaciones en los dos últimos decenios. Las reformas de la política industrial de fines de la década de 1970, particularmente en la industria automotriz, dieron mayor impulso a estos procesos. En consecuencia, los incentivos otorgados después mediante un tipo de cambio extremadamente competitivo y las reformas al comercio de mediados del decenio de 1980 cayeron en terreno que ya era fértil. Por lo tanto, el notable desempeño exportador de la industria manufacturera mexicana es en gran medida un legado del período de sustitución de importaciones y pone de relieve su éxito de manera muy fehaciente: ciertamente, condujo a un cambio irreversible de la estructura de ventajas comparativas de la economía.

Cabe ahora preguntarse cuáles fueron los efectos dinámicos de la liberalización comercial en la productividad y el crecimiento. ${ }^{27}$ En la economía en su conjunto, la productividad de la mano de obra ha estado

\footnotetext{
${ }^{27}$ Véase un análisis más detallado en Ros (1992 y 1993).
} 
estancada desde comienzos de la década de 1980, comparada con un crecimiento tendencial del orden de 4\% al año en el período 1950-1973 (cuadro 7), tanto en el período anterior como el posterior a la reforma del comercio de 1985. Al mismo tiempo, el período posterior a esa liberalización comercial, comparado con la primera mitad del decenio, registra una reactivación del aumento de la productividad en la industria manufacturera. Pese a que es difícil separarla de otros efectos -incluidos aquellos generados por las privatizaciones, la política industrial y la caída del tipo de cambio real entre 1988 y 1994-, la liberalización del comercio parece haber contribuido positivamente al incremento de la productividad en una serie de industrias manufactureras, en las que ha facilitado el aumento de la especialización intraindustrial (e intraempresas) o ha desplazado a los productores menos eficientes. Sin embargo, expresado en función del desempeño de la productividad, en otros casos los beneficios del ingreso de importaciones resultan mucho más dudosos y revelan también el rápido desplazamiento de los productores locales provocado por la mayor exposición a la competencia externa. En este caso, la llegada de importaciones ha tenido por consecuencia un deterioro de la producción y de la productividad, ya sea en comparación con la evolución histórica o con el período inmediatamente anterior a la liberalización comercial.

Así, aunque en un número limitado de sectores la liberalización del comercio (y de las inversiones

CUADRO 7

México: Empleo, horas de trabajo y productividad de la mano de obra

\begin{tabular}{lcccc}
\hline & 1950 & 1973 & 1990 & 1998 \\
\hline $\begin{array}{l}\text { PIB por persona empleada }^{\mathrm{a}} \\
\begin{array}{l}\text { Productividad de la mano } \\
\text { de obra }\end{array}\end{array}$ & 7685 & 18399 & 20747 & 20810 \\
$\begin{array}{c}\text { Empleo como porcentaje } \\
\text { de la población }\end{array}$ & 3,6 & 8,9 & 10,1 & 10,0 \\
\hline & 30,8 & 26,3 & 29,4 & 32,0 \\
\hline & $1950-$ & $1973-$ & $1973-$ & $1990-$ \\
& 1998 & 1990 & 1998 \\
\hline
\end{tabular}

Crecimiento del PIB

por hora trabajada ${ }^{\mathrm{c}}$

$4,1 \quad 0,5 \quad 0,7 \quad-0,04$

Fuente: Maddison (2001)

a Dólares a valores internacionales de 1990 .

b PIB por hora trabajada (dólares por hora a valores internacionales de 1990).

c Tasa anual media compuesta de crecimiento. extranjeras) ha tenido por consecuencia un rápido incremento de las exportaciones y de la productividad de la mano de obra, en general el crecimiento económico continúa siendo discutible. Finalmente, entre 1996 y 2000 se reanudó el crecimiento del PIB a tasas relativamente elevadas, pero en un entorno internacional excepcionalmente favorable. La verdad es que la reactivación no duró mucho. Con el tiempo, la renovada apreciación del peso desaceleró el auge de las exportaciones, y la recesión económica que se inició en los Estados Unidos en 2001 puso fin al breve período de crecimiento impulsado por las exportaciones. Desde ese año, la economía se ha estancado y lo más probable es que en 2003 el ingreso per cápita disminuya por tercer año consecutivo. Todavía no hay muestras de crecimiento económico acelerado y sostenido.

Esta experiencia plantea serias dudas de que la actual estructura industrial sea capaz de generar desarrollo autosostenido. La contrapartida de los procesos de especialización comercial intraempresas e intraindustrias es que, pese a su dinamismo, muchos — si no la totalidad- de los sectores y empresas exportadores carecen de eslabonamientos internos, y otras industrias han sido testigo de la "desintegración de los eslabonamientos". ${ }^{28}$ Por otra parte, el creciente predominio de la industria maquiladora en las actividades exportadoras es motivo de preocupación. Una de las características de esta industria son las escasas posibilidades de que aumente su productividad, en contraposición a su elevada capacidad de absorber empleo. Como en el último tiempo ha vuelto a apreciarse el tipo de cambio y, expresados en dólares, los salarios han aumentado, el bajo nivel y el estancamiento de la productividad de la mano de obra han hecho bajar los márgenes de utilidad. Unido a la recesión estadounidense, esto ha frenado la expansión de la capacidad productiva y el producto del sector de maquila, generando una acentuada baja del empleo a partir del tercer trimestre de 2000. Al no crecer la productividad, la industria maquiladora es un sector que sólo puede crecer si paga salarios bajos. Como en otros sectores los salarios tienden a elevarse al aumentar la productividad, para mantener la "competitividad interna" de las maquiladoras, es decir, su capacidad de atraer recursos desde el resto

\footnotetext{
${ }^{28}$ Dussel (2000) lo describe en un estudio casuístico sobre la industria farmacéutica, en la cual la participación de materias primas producidas en el país se redujo de alrededor de $80 \%$ a fines de los años ochenta a $20 \%$ en 1998 .
} 
de la economía, sería preciso que la moneda estuviese permanentemente subvaluada. ${ }^{29}$

\section{Liberalización financiera, auge de capitales y crisis financiera}

Si los efectos de las reformas del mercado en la eficiencia y la productividad no han podido compensar la pérdida de potencial de crecimiento del decenio de 1980, cabe preguntarse cuáles fueron los efectos de tales reformas en la afluencia de capitales externos y las posibilidades de aumentar la tasa de acumulación por este medio. ¿Podría el cambio de la relación mercado-Estado dar lugar a un flujo sostenidamente más alto de ahorro externo, lo bastante superior a las tasas históricas como para permitir el aumento de la tasa de acumulación pese al acentuado descenso de la tasa de ahorro interno? Así lo creyeron muchos observadores optimistas a comienzos de la década de 1990, para quienes México, modelo de reformas y exitoso mercado emergente, se convertiría en milagro económico latinoamericano. Este optimismo llegó a su punto culminante cuando se aprobó el TLC de América del Norte, en 1993.

Las reformas del mercado y perturbaciones externas positivas como la caída de las tasas de interés en el extranjero a principios del decenio de 1990, unidas al inicio de las negociaciones del TLC, contribuyeron por tres vías fundamentales a generar una bonanza de capitales entre 1990 y 1993 (Ros, 1994). La primera fue la liberalización de los mercados financieros internos. La segunda, una reducción drástica de la prima del riesgo-país (el mejoramiento de la imagen de México como "buen lugar donde invertir") a raíz del acuerdo para aliviar la carga de la deuda, la caída de las tasas de interés internacionales y la amortización de la deuda externa, financiada con los cuantiosos ingresos de las privatizaciones en el período 1991-1992. La tercera, que interactuó con la baja del indicador del riesgopaís, fue la apreciación real del peso y las elevadas tasas de interés que predominaron en las etapas iniciales del programa antiiinflacionario de fines de 1987.

La cuantía y la composición de los flujos de capital, que se inclinaron marcadamente hacia las inversiones de cartera de corto plazo, tuvieron tres consecuencias para la economía. En primer lugar, la sostenida apreciación del tipo de cambio real, que se pro-

\footnotetext{
${ }^{29}$ Para un análisis de los resultados de la industria maquiladora en los años noventa, véase Frenkel y Ros (2003).
}

ducía en pleno proceso de liberalización radical del comercio dio lugar a un contracción de las utilidades en los sectores de bienes transables de la economía, con consecuencias negativas para la inversión (Ros, 2001). Segundo, como resultado de las dificultades para intervenir en la afluencia masiva de capitales, la asignación de los recursos a favor del consumo y no de la inversión (Trigueros, 1998) reforzó la caída de la tasa de ahorro privado, mientras que la tendencia a producir bienes no transables, unida a la apreciación real, desaceleró la expansión económica. Por último, la creciente debilidad financiera, resultante de la concentración de las corrientes de capital en activos de elevada liquidez, acompañó el deterioro gradual de los balances del sistema bancario (Trigueros, 1998).

Estas tendencias deberían haber sido motivo de legítima inquietud para la política económica. Pero no lo fueron. En 1993, el déficit en cuenta corriente alcanzó a alrededor de $6 \%$ a $7 \%$ del PIB, y a principios de 1994 la racha de capitales había llegado a su fin. A lo largo de 1994, las autoridades agotaron las reservas internacionales para financiar el enorme déficit en cuenta corriente. No hay duda alguna de que el gobierno se equivocó en su diagnóstico de las causas de los desequilibrios macroeconómicos, puesto que pensó que las presiones sobre las reservas y los problemas que enfrentaban las autoridades encargadas de formular las políticas eran de carácter transitorio y se corregirían sin que fuera necesario depreciar el tipo de cambio. Éste no fue objeto de una devaluación importante, por estimarse que ello desataría la inflación y "enviaría señales alarmantes al mercado", aumentaría la salida de capitales y desencadenaría una crisis de balanza de pagos. En todo caso, esa política era estable, pero seguramente estaba siendo considerada no sostenible por los inversionistas en los mercados de capital y monetarios mexicanos. En el transcurso del año, el Banco de México no sólo tuvo que autorizar el alza de las tasas de interés sobre los CETES (certificados de la Tesorería) y los "tesobonos" (bonos del Tesoro mexicano), sino también otorgar mayores garantías sobre las tasas de rentabilidad de los valores del gobierno pagaderos en moneda nacional pero vinculados al tipo de cambio nominal del dólar. En todo caso, las reservas de divisas siguieron mermando y finalmente obligaron a reconocer que la política macroeconómica no era sustentable. A fines de 1994, escasamente un año después de la entrada en vigor del TLC de América del Norte, la economía mexicana se encontró en medio de una crisis financiera y al borde de experimentar la peor recesión desde la gran crisis del decenio de 1930. 
Además, a lo largo de 1994, el país enfrentó una situación de inestabilidad y violencia política, que comenzó en enero con el levantamiento armado de los zapatistas (el mismo día que entró en vigor dicho tratado).

El ciclo de auge y caída que culminó con la crisis bancaria de los años 1994-1995 se debió, al menos en parte, a una excesiva confianza en la desregulación financiera y la liberalización del mercado de capitales (Clavijo y Boltvinik, 2000; Lustig, 2002; OCDE, 2002). Lo que quedó de ese ciclo fue un sistema bancario en bancarrota, cuyo rescate significó aumentar la deuda pública en 20 puntos porcentuales del PIB, y dejar a hogares y empresas - principalmente pequeñas y medianas - sin acceso a financiamiento externo y prácticamente sin poder acceder al crédito bancario. Al respecto, parece irónico que el sector bancario tuviera que volver a racionar el crédito, como lo había hecho durante la era de restricción financiera que precedió a la liberalización financiera de fines de la década de 1980. Esta situación ha impedido un crecimiento más acelerado y ha fortalecido la dicotomía del sector productivo. ${ }^{30}$

\section{El crecimiento del último tiempo y el desem- peño de la inversión}

Tras su caída de 6,2\% del PIB real en 1995 - la mayor baja en más de 50 años- el crecimiento económico se reanudó en el período 1996-2000. Sin embargo, esta expansión se interrumpió súbitamente en los años 2001-2002 y el PIB per cápita se redujo en términos reales. En promedio, entre 1985 y 2002 el PIB per cápita aumentó a una tasa de 2,2\% anual, es decir, apenas medio punto porcentual por encima de la tasa de crecimiento de la población. Además, según las cifras más recientes, el PIB per cápita mexicano se mantuvo estancado en 2003. Así, se estima que medido en dólares de valor constante, para entonces fue equivalente a poco más del $20 \%$ del PIB per cápita correspondiente de los Estados Unidos. La diferencia sería casi 10 puntos porcentuales mayor que en 1981 y similar a la registrada cincuenta años antes. En otras palabras, durante estos cinco decenios el PIB per cápita real de México no ha logrado aproximarse de manera significativa al de su vecino del norte.

\footnotetext{
${ }^{30}$ Giugale, Lafourcade y Nguyen (2001) y Dussel (2000) muestran que la reducción de los créditos afectó de distinta manera a las grandes empresas y a las empresas pequeñas y medianas, y que la diferencia en el desempeño de las exportaciones de ambos tipos de empresas fue creciente.
}

Uno de los aspectos cruciales de la desaceleración de la tasa de crecimiento económico de México ha sido el precario comportamiento de la inversión. ${ }^{31} \mathrm{El}$ hecho de que la acumulación de capital no aumentara con rapidez - tras los años de baja durante la crisis de la deuda - ha impedido ampliar y modernizar la capacidad productiva y, al mismo tiempo, ha limitado el incremento de la demanda agregada. De hecho, la inversión fija bruta tuvo una trayectoria similar a la del PIB en términos reales. Aumentó rápidamente durante el auge del petróleo, para desplomarse en el período 1982-1987 y empezar a recuperarse lentamente en 1988 (gráfico 2). Esta recuperación se afianzó en alguna medida en 1991-1992, respondiendo a las expectativas favorables asociadas al comienzo de las negociaciones del TLC de América del Norte. La recuperación se detuvo en 1995, pero luego avanzó vigorosamente en el período 1996-2000. Sin embargo, en 20012002 la inversión volvió a caer en términos reales. En síntesis, durante los últimos dos decenios, la inversión dejó mucho que desear.

El comportamiento desalentador de la inversión es razón para preocuparse del crecimiento económico de México en el futuro. ¿Qué lo ha causado? ¿Es posible que las reformas macroeconómicas hayan adolecido de limitaciones o inconvenientes que impidieran tener en cuenta o interpretaran erradamente la naturaleza de los elementos clave que determinaron el proceso de inversión en el país? Investigaciones recientes sobre el tema han identificado un conjunto de factores que contribuyen a explicar el deficiente desempeño de la inversión en México (Moreno-Brid y Peres, 2003).

En primer lugar, las reformas se adoptaron en una economía estancada que racionaba estrictamente el acceso a capitales y financiamiento externos o internos. El entorno económico adverso se agravó por la caída de la inversión pública, porque históricamente los efectos de complementación entre la inversión pública y la privada han sido más importantes que los de desplazamiento (UNCTAD, 2003).

Además, las reformas estaban expresamente destinadas a eliminar todo tipo de incentivos, entre ellos las medidas para fomentar la inversión interna tanto agregada como en sectores específicos. No se hizo intento alguno por canalizar el gasto interno hacia la

\footnotetext{
31 Véase en Moreno-Brid (1999) y Moreno-Brid y Peres (2003), un amplio análisis del comportamiento de la inversión en el sector manufacturero mexicano después de las reformas macroeconómicas.
} 
GRAFICO 2

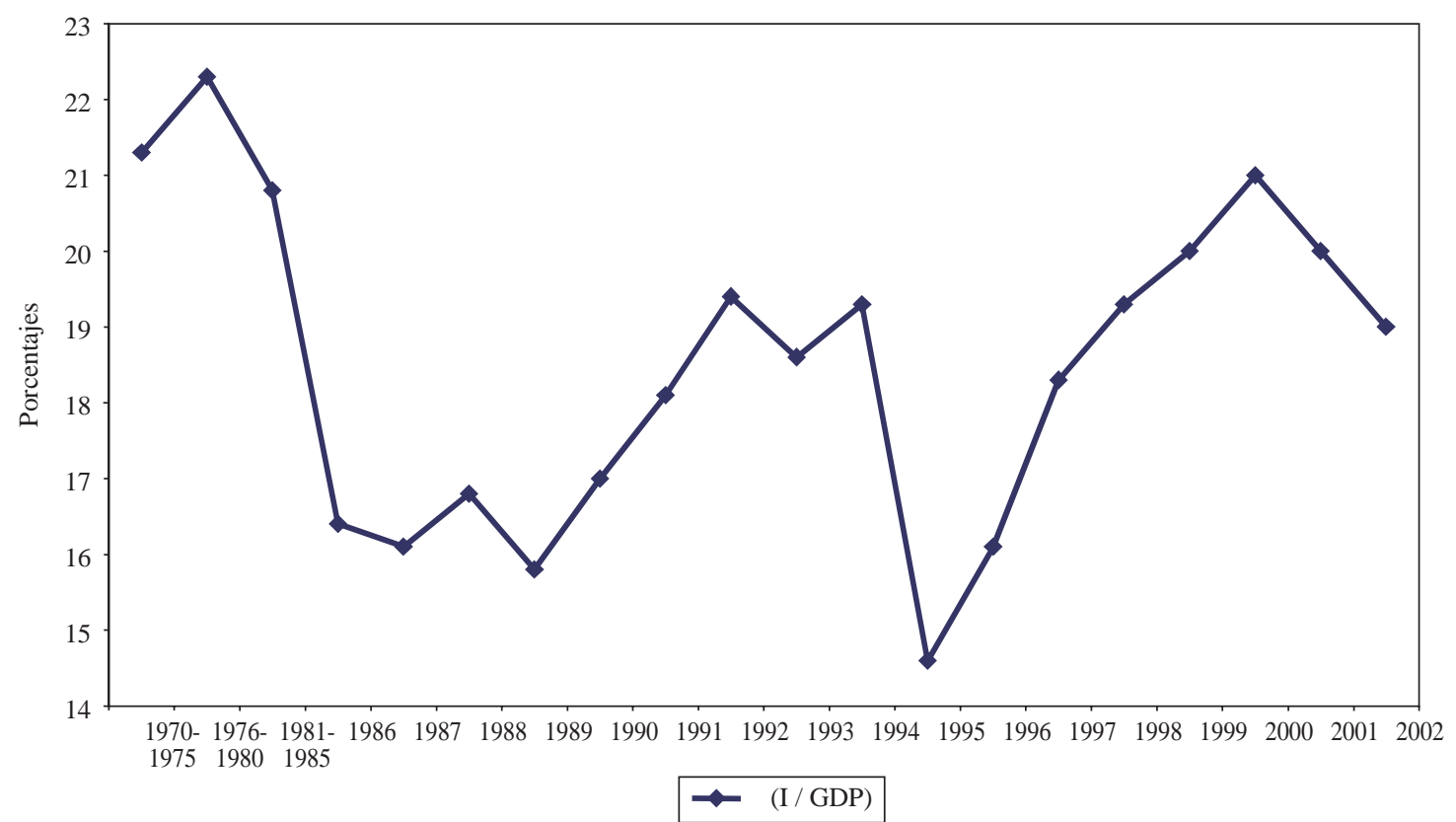

Fuente: Elaborado por los autores a partir del cuadro 4 de Moreno-Brid y Peres, basado en datos de la CEPAL y del INEGI.

a Las cifras correspondientes al período 1970-1988 se calcularon a partir de datos de 1980 y las correspondientes a 1989-2001 en datos de 1993, en ambos casos en pesos constantes.

inversión en vez de hacia el consumo. A este expreso rechazo del fomento de la inversión se sumó la incertidumbre inherente a cualquier cambio radical en la estrategia de desarrollo. Desde luego, lejos de favorecer la inversión esta incertidumbre llevó a aplazar o interrumpir proyectos de inversión. La eliminación de los incentivos sectoriales perjudicó especialmente las inversiones en manufacturas, dado que la industria manufacturera había sido el sector más favorecido por el anterior modelo de desarrollo basado en la sustitución de importaciones y la industrialización impulsada por el Estado. Exacerbados por la intensa y repentina competencia de las importaciones, los desincentivos redujeron la rentabilidad relativa de la industria manufacturera y esta a su vez frenó la inversión. La apreciación del tipo de cambio real respecto del dólar de los Estados Unidos en 1988-1994 contribuyó a desalentar aún más a la inversión en la industria manufacturera $\mathrm{y}$, de manera más general, en el sector de bienes transables. Si bien es cierto que en los países en desarrollo la apreciación del tipo de cambio real puede estimular la inversión fija, al reducir los precios relativos de la maquinaria y el equipo importados, también modifica los precios relativos a favor de los bienes no transables, e induce a reasignar la mano de obra y la inversión, desplazándolos de la producción de bienes y servicios transables. Al parecer, en México predominó este último efecto.

\section{La reforma del Estado y la labor que corres- ponde a la política de desarrollo}

La otra cara de las reformas del mercado es la retirada del Estado y su reestructuración. Se argumenta que al disminuir de tamaño aumentan las posibilidades de que el Estado pueda cumplir mejor sus funciones prioritarias. Sin embargo, que el Estado sea más pequeño no significa necesariamente que sea más eficaz. De acuerdo con las normas internacionales, la carga impositiva mexicana continúa siendo extremadamente baja (OCDE, 2002). Los ingresos tributarios como porcentaje del PIB, que a fines de la década de 1990 llegaban a un 12\%, son menores que en países latinoamericanos con ingresos per cápita similares, y mucho menores que en los países de la OCDE. Como resultado, las cuentas fiscales siguen estando muy expuestas a las oscilaciones del 
ingreso proveniente del petróleo, que aún representa alrededor de un tercio de las entradas totales del gobierno. Junto con la pérdida de mecanismos de política, la reorientación del objetivo de la política monetaria desde el crecimiento a la mera estabilización y la inestabilidad de los flujos de capital externo, esto origina un grave problema macroeconómico, pues contribuye a generar políticas macroeconómicas procíclicas que agudizan los efectos negativos de las perturbaciones externas en la actividad económica.

Tampoco el Estado es siempre más eficiente. El ajuste fiscal efectuado en México - pese a su carácter masivo, o tal vez debido a él- no estimuló una mayor eficiencia interna del sector público. A la larga, especialmente antes de 1985, el ajuste fiscal se logró mediante grandes recortes de la inversión pública y del salario real de los funcionarios públicos, lo que dista mucho de ser la mejor manera de acrecentar la eficiencia del Estado y de su burocracia. Además, el Estado se retiró no sólo de las esferas en que el sector privado tiene ventajas comparativas, sino de muchas otras. La verdad es que la principal víctima del ajuste fiscal tras la caída de los precios del petróleo fue la inversión pública en infraestructura. En el estudio de Giugale, Lafourcade y Nguyen (2001) se ilustra vívidamente, con dos cifras, la estrecha correlación entre las bajas de los precios del petróleo, los recortes del déficit fiscal y la reducción de la inversión pública (entre 1980 y 1997, el coeficiente de correlación entre los dos últimos fue de 0,82). Como consecuencia, en el período 2001-2002 la inversión pública alcanzó apenas a un 3\% del PIB, en comparación con 5\% en 1994 y 10\% en el período 1980-1981 (cuadro 6). Pese a algunas tendencias positivas recientes en el gasto social, es evidente que la renuncia del Estado a participar en algunas actividades no ha logrado su finalidad principal, esto es, el mejoramiento de la infraestructura social. La contribución más importante de los ingresos provenientes de las privatizaciones fue la de apoyar (sin duda muy eficazmente) los intentos de estabilización, contrarrestando transitoriamente la caída del impuesto inflación y fortaleciendo la cuenta de capital de la balanza de pagos mediante los activos financieros que el sector privado debió traer de vuelta al país para comprar las empresas públicas que estaban en venta.

Lo que todo esto implica tiene más importancia que la que usualmente se le reconoce, puesto que las funciones prioritarias del Estado - en especial la política social— son hoy formidables, muchísimo más que en el pasado, por varias razones. En primer lugar, tienen que habérselas con el cúmulo de necesidades sociales insatisfechas y con el legado de mayor desigualdad que dejó la década de 1980. Debido al lento crecimiento de la agricultura y a la expansión del sector urbano informal, la reactivación del gasto social en el decenio de 1990 no logró impedir que aumentara el número de pobres ni que se mantuviera una marcada desigualdad en la distribución del ingreso. Lustig (2002) muestra que la desigualdad de los ingresos, medida por el coeficiente de concentración de Gini, aumentó pronunciadamente (alrededor de cuatro puntos porcentuales) entre 1984 y 1989, para caer luego entre 1989 y 1994 (aunque manteniéndose levemente por encima de su nivel de 1984). Según estimaciones de la OCDE (2002), entre 1994 y 2000 hubo un ligero aumento de la desigualdad de los ingresos: el coeficiente de Gini se elevó de 0,477 a 0,481. Los índices de pobreza extrema y de pobreza moderada exhibieron un comportamiento similar a través del tiempo, mientras el número de pobres aumentó en forma sostenida hasta 1994.

En segundo lugar, la actual modalidad de desarrollo exacerba las disparidades sociales al menos de dos maneras. Si bien el retiro del Estado desde la agricultura y la reforma del sistema de tenencia de la tierra significó capitales privados y prosperidad para algunas zonas rurales, también tendieron involuntariamente a empobrecer a una gran masa de trabajadores rurales, tal como lo hizo deliberadamente y de manera mucho más masiva la modernización de la agricultura durante el porfiriato. El comportamiento de la agricultura comercial que produce bienes exportables se vio favorecido por las reformas y respondió positivamente a ellas (en los cinco primeros años de vigencia del TLC de América del Norte las exportaciones aumentaron $70 \%$ ). El sector ejidal, en cambio, ha tenido un comportamiento muy diferente, ya que no se ha visto igualmente beneficiado (las importaciones aumentaron $60 \%$, afectando a este sector que produce sobre todo bienes importables). En la actualidad, subsiste apenas, gracias a su creciente incorporación a actividades no agrícolas: alrededor de $40 \%$ de sus ingresos proviene de fuentes no agrícolas, incluidas remesas (Giugale, Lafourcade y Nguyen, 2001). Como lo reconocen estos autores, el estancamiento general de la producción agrícola y la persistencia de la pobreza rural guardan relación con las reformas mismas. La eliminación de la protección comercial $-\mathrm{y}$ la sobreevaluación del tipo de cambio en la primera parte del decenio- contribuyeron a fortalecer la tendencia a la baja de los precios agrícolas reales. Por otra parte, la eliminación 
de los programas de difusión y de asistencia técnica ha afectado a gran parte de los pequeños productores. Cuando el Estado dejó de participar en la distribución de los productos, los canales de comercialización fueron dominados por intermediarios oligopolistas que disminuyen los precios al productor, perjudicando en especial a las zonas más pobres. La liberalización no produjo los beneficios esperados debido a la falta de mercados competitivos y al hecho de que no se tuvo debidamente en cuenta la amplia diversidad regional y la heterogeneidad de ingresos que se da en el campo mexicano.

Por otra parte, dentro del país también se están distribuyendo muy desigualmente los beneficios de una mayor inserción en la economía internacional, particularmente en la estadounidense. La mayor integración se ha acompañado de un apreciable aumento de la prima salarial por concepto de mano de obra especializada y la consiguiente baja relativa del ingreso de la mano de obra no calificada, causa importante de la persistente desigualdad. Como lo demuestran Godínez (2000) y Dussel (2000), entre 1970 y 1985 las tendencias regionales en general apuntaron hacia la desconcentración de la actividad económica (alejándola de los principales centros industriales de la zona metropolitana de Ciudad de México, Nuevo León y Jalisco) y a la convergencia de los niveles de ingreso regionales. A partir de 1988 se ha estado produciendo un proceso de divergencia, en especial debido a que los estados del norte vinculados con las actividades exportadoras han estado aumentando rápidamente su participación en el ingreso nacional. En cambio, se ha rezagado el sur, que es relativamente pobre (salvo Quintana Roo, que se vio favorecido por la expansión del turismo). Estas tendencias regionales guardan clara relación con los cambios estructurales de la economía, como ser el rezago de la producción de cereales, la expansión de los sectores exportadores de productos agroindustriales, frutas y hortalizas, y el crecimiento acelerado de las actividades manufactureras orientadas hacia las exportaciones de las zonas norte y central del país. Así como a fines del siglo XVIII la "apertura del comercio con el Atlántico norte" agudizó la "fragmentación de los mercados regionales", actualmente se observa una tendencia a profundizar las disparidades regionales, especialmente entre un norte próspero y cada vez más integrado a la economía estadounidense y un sur pobre y atrasado, sumido en el estancamiento agrícola.

Finalmente, y no por ello menos importante, al abandonar sin reemplazo eficaz los mecanismos de política comercial e industrial que habían surtido efecto en el pasado, la actual estrategia de desarrollo estimula la explotación de las ventajas comparativas reales antes que las potenciales. A falta de una política industrial, ahora recae plenamente en las políticas sociales la tarea fundamental de la política de desarrollo: la de modificar y mejorar la actual dotación de recursos y desplazar con el tiempo el patrón de ventajas comparativas hacia actividades de mayor valor agregado y uso intensivo de tecnología. En rigor, una respuesta proporcionada a este desafío podría mejorar la situación más que si se aplicara una política industrial activa con poca política social, pero lo que deseamos destacar es que el desafío mismo es mucho mayor y la respuesta está por verse. En cambio, una respuesta desproporcionada llevaría a congelar la actual etapa de desarrollo, es decir, a entramparse en las labores relativamente poco especializadas y mal remuneradas de los procesos productivos de las industrias que hacen uso intensivo de capital. Esta perspectiva dista mucho de ser deseable para un país que necesita crecer rápidamente para mejorar las condiciones de vida de sus 100 millones de habitantes.

\section{V}

\section{Observaciones finales}

Lo anterior nos lleva al aspecto final y más importante del proceso general de reformas, respecto del cual sólo podemos plantear las interrogantes del caso. La modificación del equilibrio mercado-Estado ¿es quizá señal de que tras haber reducido el atraso económico mediante la industrialización patrocinada por el Estado, en la nueva etapa conviene más aplicar un conjunto de ideas diferente, un cambio que acompañe de manera natural la transición desde una actividad empresarial gerschenkroniana a otra de tipo schumpeteriano? $\mathrm{O}$, en palabras del propio Gerschenkron (1952), ¿será que para romper las barreras del estancamiento en un país atrasado, despertar la imaginación de las personas y poner sus energías al servicio del desarrollo económico, 
se necesita una medicina más potente que la simple promesa de mejorar la asignación de recursos? Encarar estas interrogantes es algo que escapa al alcance del presente trabajo y a las posibilidades de sus autores. Pero de las respuestas dependen las perspectivas de desarrollo económico acelerado a largo plazo que tiene México.

Lo que sí podemos decir, sin embargo, es que la actual política de desarrollo no ha captado adecuadamente cuál es el origen de los problemas de ajuste y de los nuevos problemas creados por el proceso de reformas. En primer lugar, por mucho que no estemos dispuestos a defender todos los aspectos de las estrategias de desarrollo que se han aplicado en el pasado, no habría que dar por sentado que la crisis se debió al agotamiento de dichas estrategias. Segundo, para superar los nuevos obstáculos es posible que se requiera una participación mayor y mejor del Estado, y no lo contrario. Como hemos tratado de demostrar, la fuente de estos nuevos problemas debe buscarse en parte en la menor intervención del Estado, en campos tales como la inversión pública en infraestructura. Sin embargo, debido al cambio del entorno ideológico, se está prestando muy poca atención a estos problemas y a lo que podría hacer la política de gobierno al respecto, mientras que a la vez se espera demasiado de la mayor eficiencia que traerían consigo las reformas del mercado. Cabe preguntarse si, como sucedió un siglo y medio atrás, hay una errada percepción de los verdaderos obstáculos que dificultan el desarrollo económico.

\section{Bibliografía}

Aschauer, D.A. (1989a): Is public expenditure productive?, Journal of Monetary Economics, vol. 23, $\mathrm{N}^{\circ}$ 2, Rochester, Simon Graduate School of Business Administration, University of Rochester.

(1989b): Does public capital crowd out private capital?, Journal of Monetary Economics, vol. 24, No 2, Rochester, Simon Graduate School of Business Administration, University of Rochester.

(2000): Public capital and economic growth: issues in quantity, finance and efficiency, Economic Development and Cultural Change, vol. 48, $\mathrm{N}^{\circ}$ 2, Chicago, The University of Chicago Press.

Beatty, E. (2001): Institutions and Investment, Stanford, Stanford University Press.

(2002): Commercial policy in Porfirian Mexico: the structure of protection, en J.L. Bortz y S. Haber, The Mexican Economy, 1870-1930. Essays on the Economic History of Institutions, Revolution and Growth, Stanford, Stanford University Press.

Bortz, J. y S. Haber (2002): The Mexican Economy, 1870-1930: Essays on the Economic History of Institutions, Revolution, and Growth, Stanford, Stanford University Press.

Cárdenas, E. (1985): Algunas cuestiones sobre la depresión mexicana del siglo XIX, Revista latinoamericana de historia económica y social, $\mathrm{N}^{\mathrm{o}} 3$, Lima.

Cárdenas, E. y C. Manns (1989): Inflación y estabilización monetaria en México durante la revolución, El trimestre económico, vol. 56, No 221, México, D.F., Fondo de Cultura Económica, enero-marzo.

Clavijo, F. y J. Boltvinik (2000): La reforma financiera, el crédito y el ahorro, en F. Clavijo (comp.), Reformas económicas en México 1982-1999, Lecturas El trimestre económico, No 92, México, D.F., Fondo de Cultura Económica.

Coatsworth, J. (1978): Obstacles to economic growth in nineteenthcentury Mexico, The American Historical Review, vol. 83, $\mathrm{N}^{\circ} 1$, Washington, D.C., American Historical Association, febrero. (1989): The decline of the Mexican economy, 1800-1860, en R. Liehr (comp.), América Latina en la época de Simón Bolivar, Berlín, Colloquium Verlag.

(1990): Los orígenes del atraso. Nueve ensayos de historia económica de México en los siglos XVIII y XIX, México, D.F., Alianza Editorial Mexicana.
Cordera R. y L. Lomelí (2000): Sobre el presidencialismo económico y su crepúsculo, Comercio exterior, vol. 50, № 11, México, D.F., Banco Nacional de Comercio Exterior, noviembre.

Deno, K.T. (1988): The effect of public capital on U.S. manufacturing activity: 1970 to 1978, Southern Economic Journal, vol. 55, Oklahoma, Southern Economic Association.

Dussel Peters, E. (2000): Polarizing Mexico. The Impact of Liberalization Strategy, Boulder, Colorado, Lynne Rienner Publishers.

Easterly, W. y S. Rebelo (1993): Fiscal policy and economic growth: an empirical investigation, Journal of Monetary Economics, vol. 32, No 3, Rochester, Simon Graduate School of Business Administration, University of Rochester.

Frenkel, R. y J. Ros (2003): Macroeconomic policies, trade specialization, and labor market adjustment in Argentina and Mexico, University of Notre Dame, inédito.

Garcia Alba, P. (1974): Los liberales y los bienes del clero, México, D.F., El Colegio de México.

Gerschenkron, A. (1952): Economic backwardness in historical perspective, en B. Hoselitz (comp.), The Progress of Underdeveloped Countries, Chicago, University of Chicago Press.

Gil Diaz, F. (1984): Mexico's path from stability to inflation, en A. Harberger (comp.), World Economic Growth, San Francisco, Institute for Contemporary Studies.

Giugale, M., O. Lafourcade y V.H. Nguyen (comps.) (2001): Mexico: A Comprehensive Development Agenda for the New Era, Washington, D.C., Banco Mundial.

Godínez, V.M. (2000): La economía de las regiones y el cambio estructural, en F. Clavijo (comp.), Reformas económicas en México, 1982-1999, serie Lecturas El trimestre económico, $\mathrm{N}^{\circ}$ 92, México, D.F., Fondo de Cultura Económica.

Haber, S. (1989): Industry and Underdevelopment: The Industrialization of Mexico, 1890-1940, Stanford, Stanford University Press.

Hernández Laos, E. (1990): Política de desarrollo industrial y evolución de la productividad total de los factores en la industria manufacturera mexicana, Informe presentado al Fondo de Estudios Ricardo J. Zevada, México, D.F., Universidad Autónoma Metropolitana.

INEGI (Instituto Nacional de Estadística, Geografía e Informática) (1985): Estadísticas históricas de México, México, D.F. 
King, T. (1970): Mexico: Industrialization and Trade Policies since 1940, Oxford, Oxford University Press.

Kuntz Ficker, S. (2002): Institutional change and foreign trade in Mexico, 1870-1911, en J.L. Bortz y S. Haber, The Mexican Economy, 1870-1930. Essays on the Economic History of Institutions, Revolution and Growth, Stanford, Stanford University Press.

Lustig, N. (2002): México: hacia la reconstrucción de una economía, México, D.F., El Colegio de México/Fondo de Cultura Económica.

Maddison, A. (1989): The World Economy in the 20th Century, París, Centro de Desarrollo de la Organización de Cooperación y Desarrollo Económicos (OCDE)

(2001): The World Economy: A Millenial Perspective, París, Organización de Cooperación y Desarrollo Económi$\cos (\mathrm{OCDE})$

Manzanilla Schaffer, Y. (1963): Reforma agraria en México, México: 50 años de revolución, México, D.F., Fondo de Cultura Económica.

Moreno-Brid, J.C. (1988): The Motor-Vehicle Industry in Mexico in the Eighties, Ginebra, Organización Internacional del Trabajo (OIT).

(1999): Mexico's economic growth and the balance of payments: a co-integration analysis, International Review of Applied Economics, vol.13, № 2, Londres, Routledge.

Moreno-Brid, J.C. y E. Pérez (2003): Liberalización comercial y crecimiento económico en Centroamérica, Revista de la CEPAL, $\mathrm{N}^{\circ}$ 81, LC/G.2216-P, Santiago de Chile, diciembre.

Moreno-Brid, J.C. y J. Ros (1994): Market reform and the changing role of the State in Mexico: a historical perspective, en A. Dutt, K. Kim y A. Singh (comps.), The State, Markets and Development, Cheltenham, Edward Elgar Publishing.

Mosk, S. (1950): Industrial Revolution in Mexico, Berkeley, University of California Press.

Munnell, A. (1990): How does public infrastructure affect regional economic performance?, en A. Munnell (comp.), Is there a Shortfall in Public Capital Investment?, Conference Series $\mathrm{N}^{\circ} 34$, Boston, Federal Reserve Bank of Boston.

Newell, R. y L. Rubio (1984), Mexico's Dilemma: The Political Origins of the Economic Crisis, Londres, Westview Press.

Nugent, J.B. (1973): Exchange rate movements and economic development in the late XIX Century, Journal of Political Economy, vol. 84, $\mathrm{N}^{\circ}$ 5, Chicago, The University of Chicago Press, septiembre-octubre.

OCDE (Organización de Cooperación y Desarrollo Económicos) (2002): OECD Economic Surveys, París.

Polanyi, K. (1944): The Great Transformation, New York y Toronto, Farrar and Rinehart, Inc.
Ros, J. (1992): Mexico's Trade and Industrialization Experience since 1960: a Reconsideration of Past Policies and Assessment of Current Reforms, Helsinki, Instituto Mundial de Investigaciones de Economía del Desarrollo (WIDER).

(1993): Trade Liberalization with Real Appreciation and Slow Growth: Sustainability Issues in Mexico's Trade Policy Reform, Helsinki, Instituto Mundial de Investigaciones de Economía del Desarrollo (WIDER)

(1994): Financial markets and capital flows in Mexico, en J.A. Ocampo y R. Steiner, Foreign Capital in Latin America, Washington, D.C., Banco Interamericano de Desarrollo (BID).

(2001): Del auge de capitales a la crisis financiera y más allá: México en los noventa, en Ricardo Ffrench-Davis (comp.), Crisis financieras en países "exitosos", Santiago de Chile, CEPAL/McGraw Hill.

Rosenzweig, F. (1965): El desarrollo económico de México de 1877 a 1911, El trimestre económico, vol. 32, № 5, México, D.F., Fondo de Cultura Económica.

Solis, L. (1977): A Monetary Will-O' the Wisp: Pursuit of Equity through Deficit Spending, Ginebra, Organización Internacional del Trabajo (OIT).

(2000): La realidad económica mexicana: retrovisión y perspectivas, México, D.F., Fondo de Cultura Económica.

Thomson, G. (1986): The cotton textile industry in Puebla during the eighteenth and early nineteenth centuries, en N. Jacobsen y H.J. Puhle (comps.), The Economies of Mexico and Peru during the Late Colonial Period, 1760-1810, Berlín, Colloquium Yerlag.

Trigueros, I. (1998): Flujos de capital y desempeño de la inversión: México, en R. Ffrench-Davis y H. Reisen (comps.), Flujos de capital e inversión productiva: lecciones para América Latina, Santiago de Chile, CEPAL/OCDE, McGraw-Hill.

UNCTAD (Conferencia de las Naciones Unidas sobre Comercio y Desarrollo) (2003), Informe sobre el comercio y el desarrollo, 2003, UNCTAD/TDR/2003, Nueva York, Naciones Unidas. Publicación de las Naciones Unidas, $\mathrm{N}^{\mathbf{0}}$ de venta: S.03.II.D.7.

Van Young, E. (1981): Hacienda and Market in Eighteenth Century Mexico: The Rural Economy of the Guadalajara Region, 16751820, Berkeley, University of California Press.

(1986): The age of paradoxes: Mexican agriculture at the end of the colonial period, 1750-1810, en N. Jacobsen y H.J. Puhle (comps.), The Economies of Mexico and Peru during the Late Colonial Period, 1760-1810, Berlín, Colloquium Verlag.

Zabludovsky, J. (1994): La depreciación de la plata y las exportaciones, en E. Cárdenas (comp.), Historia económica de México, Lecturas El trimestre económico, $\mathrm{N}^{\circ}$ 64, México, D.F., Fondo de Cultura Económica. 